ISSN (print) 0867-2008 / ISSN (online) 2391-75 I 2

DOI: http://dx.doi.org/10.12775/OM.2019.004

\title{
SŁAWOMIR ZONENBERG*
}

Instytut Historii i Stosunków Międzynarodowych

Wydział Humanistyczny

Uniwersytet Kazimierza Wielkiego w Bydgoszczy

ul. Księcia Józefa Poniatowskiego 12

PL-85671 Bydgoszcz

Poland

zonenbergs@poczta.onet.pl

\section{DER DEUTSCHE ORDEN UND DIE DOMINIKANER IN DER RIVALITÄT UM DIE PREUSSISCHEN BISTÜMER IN DER MITTE DES 13. JAHRHUNDERTS}

\author{
KEYWORDS \\ history; the Middle Ages; military orders; Teutonic Order; Dominicans; Prussia; bishoprics; conflicts
}

\begin{abstract}
The Teutonic Order and the Dominicans in the rivalry for the Prussian bishoprics in the middle of the I3th century

In I 233 the missionary bishop of Prussia Cistercian Christian got into Old Prussian captivity. He stayed there until I 236 or I237-I238. The Teutonic Order took advantage of this Christian's absence. As a result of their efforts, Pope Gregory IX impose in I 234 the land of Chelmno and Prussia in possession and at the same time handed them entirely to the owners of the Teutonic Order. However, provided that they set up a separate church organization and adequate remuneration for the bishoprics planned there. On the other hand, the Pope's decision of I 236 was to be occupied by the Dominicans. Motives - which led by Gregory IX, by issuing the above-mentioned provisions - were combined with the desire to bind the Teutonic Order and Dominicans with the Papal Curia in the face of the game played with Emperor Frederick II. The resignation from Christian could have resulted from the poor results of his activities in Prussia. The Teutonic Order decided to cooperate with the Dominicans, because at that time they did not have adequate human resources to fill the bishoprics. After the conquest of a large part of Prussia in I 236-I 240, among the decision-makers of the Teutonic Order won the view that the local episcopate - possessing a powerful fortune, $1 / 3$ of the whole land - should support their
\end{abstract}

* ORCID: https://orcid.org/0000-0002-7263-6740 
power, and only the loyal bishops could ensure the durability of such a line. As a result of the activities carried out, the Teutonic Order permanently took over three from four Prussian cathedral chapters and thus bishoprics.

$\mathrm{D}$ er Gegenstand dieses Artikels ist die Darstellung der Rivalität zwischen dem Deutschen Orden und den Dominikanern um die preußischen Bistümer um die Mitte des I 3. Jahrhunderts. Bisher ist diese Frage noch nicht behandelt worden, aber es gibt Arbeiten, welche über die Beziehungen des Deutschen Ordens mit den einzelnen preußischen dominikanischen Bischöfen informieren. ${ }^{1}$ Der Artikel wurde anhand der bekannten (ausgewerteten) Quellen verfasst. $^{2}$

Im Frühling oder Sommer des Jahres 1233 geriet der preußische Missionsbischof Christian (I215/I216-1245), der damals größte Konkurrent der Deutschordensritter in dem Wettstreit um dieses Land, in Samland in prußische Gefangenschaft. Er wurde, trotz der Bemühungen des päpstlichen Legaten Wilhelm von Modena († I 25 I) und bei gänzlicher Passivität des Deutschen Ordens, für gleich mehrere Jahre gefangen gehalten. ${ }^{3}$ Die Deutschordensritter nutzten die Abwesenheit des Bischofs. Infolge ihrer Bemühungen übernahm Papst Gregor IX. (1227-I24I) am 3. August I 234 das Kulmerland und Preußen „in ius et proprietatem beati Petri et sub speciali apostolice sedis protectione" und legte beide Gebiete zugleich in die Hände des Deutschen Ordens. Dies erfolgte jedoch unter der Bedingung, dass dort eine separate kirchliche Organisation entstehen und die

Ich zitiere sie unten in den Anmerkungen.

Vgl. Anm. I.

Siehe Pommerellisches Urkundenbuch, bearb. v. Max Perlbach (Danzig: Westpreussischen Geschichtsverein, I 882), 55 Nr. 65; sowie u. a. Max Perlbach, "Zur Geschichte der ältesten preussischen Bischöfe," Altpreußische Monatsschrift 9 ( I 872): 633; Gustav A. Donner, Kardinal Wilhelm von Sabina. Bischof von Modena I222-I234. Päpstlicher Legat in den nordischen Ländern ( $t$ I25I), Societas Scientiarum Fennica, Commentationes Humanorum Litterarum II/5 (Helsingfors: Societas Scientiarum Fennica, 1 929), S. 248; Fritz Blanke, "Die Entscheidungsjahre der Preussenmission (I206-I274)," in Heidenmission und Kreuzzugsgedanke in der Deutschen Ostpolitik des Mittelalters, hrsg. v. Helmut Beumann, Wege der Forschung 7 (Darmstadt: Wissenschaftliche Buchgesellschaft, 1963), S. 405-406; Roman Bodański, "Początki hierarchii kościelnej w Prusach. Część I," Studia Warmińskie I 6 (I979): 345, 35 I; Andrzej Radzimiński, "Geneza oraz ukształtowanie się organizacji kościelnej ( I 206-I 409)," in Państwo zakonu krzyżackiego w Prusach. Wtadza i spoteczeństwo, hrsg. v. Marian Biskup und Roman Czaja (Warszawa: Wydawnictwo Naukowe PWN, 2009), S. I 44; Paweł Grochowski, Chrystian. Biskup Prus I216-I245 i misja pruska jego czasów (Górna Grupa: Wydawnictwo Verbinum, 20 I 8), S. 207. 
dort geplanten Bistümer entsprechend ausgestattet werden sollten. ${ }^{4}$ Diese Bulle konstituierte gleichsam einen autonomen Staat des Deutschen Ordens in Preußen und schloss den Zisterzienserbischof Christian weitgehend aus "dem Spiel“ um dieses Land aus.' Ab diesem Moment wird eine engere Zusammenarbeit der Dominikaner mit dem Deutschen Orden in Preußen sichtbar, welche dort früher eingetroffen waren als die Deutschordensritter (d. h. nach I 228 und vor I 23 I). ${ }^{6}$ Die Erhaltung von entsprechender Beziehungen mit den Dominikanern war für den Deutschen Orden so wichtig, dass dieser - als die Zisterzienser ihm gegenüber nicht mehr wohlwollend waren - in ihnen einen neuen Verbündeten gewann. ${ }^{7}$ Am 29. Januar I 236 erstellte der preußische Landmeister Hermann Balk ( $230-$ - I239) in Marienwerder (poln. Kwidzyn) eine Urkunde zugunsten Dietrichs von Dypenow. Die Verfügung des Dokuments - welche sowohl für den Empfänger als auch für die Deutschordensritter günstig war, denn sie sicherte ihre Interessen ab betraf hauptsächlich Vermögens- und Militärfragen. Die Zeugen (die man auch als Vermittler verstehen sollte) in diesem Dokument waren der Pole Jacek Odrowąż ( I 83 - I 257) und der Sachse Heidenreich (ca. I 200-1 263), also zwei bedeutende

4 Preußisches Urkundenbuch. Politische (allgemeine) Abteilung, Bd. I, Die Bildung des Ordensstaats, Hälfte I, hrsg. v. Rudolf Philippi in Verbindung mit [Carl P.] Woelky (Königsberg/ /Pr.: Hartungsche Verlagsdruckerei, I 882), Nr. ı08; siehe auch Paul Reh, "Das Verhältnis des Deutschen Ordens zu den preußischen Bischöfen im i 3. Jahrhundert," Zeitschrift des Westpreußischen Geschichtsvereins 35 (1896): 55-56; Bernhart Jähnig, "Die Staufer, der Deutsche Orden und Nordosteuropa," Jahrbuch Preußischer Kulturbesitz I 6 ( I 979): I 45; Marian Biskup und Gerard Labuda, Die Geschichte des Deutschen Ordens in Preußen. Wirtschaft - Gesellschaft Staat - Ideologie (Osnabrück: Fibre Verlag, 2000), S. I 48-149; Marian Dygo, "Początki i budowa władztwa zakonu krzyżackiego (I 226-1 309)," in Państwo zakonu krzyżackiego, hrsg. v. Biskup und Czaja, 6r; Radzimiński, Geneza, i 44.

s Biskup und Labuda, Die Geschichte, I 49; siehe auch Dariusz Aleksander Dekański, Poczatti zakonu dominikanów prowincji polsko-czeskiej. Pokolenie św. Jacka w zakonie (Gdańsk: Wydawnictwo Uniwersytetu Gdańskiego, I 999), 167.

6 Werner Roth, Die Dominikaner u. Franziskaner im Deutsch-Ordensland Preußen bis zum Jahre I466 (Königsberg i. Pr.: Drewes, I 9 I 8), S. 3-4; Jan Powierski, "Dzieje ziemi pasłęckiej do schyłku XIII w.," in Pastęk: z dziejów miasta i okolic 1297-1997, hrsg. v. Jan Włodarski (Pasłęk: Urząd Miasta i Gminy, 1997), I63-165; ders., "Aspekty terytorialne cysterskiej misji w Prusach," in Cystersi w spoteczeństwie Europy Środkowej, hrsg. v. Andrzej Marek Wyrwa und Józef Dobosz (Poznań: Wydawnictwo Poznańskie, 2000), S. 264-266; Dariusz Aleksander Dekański, “Cystersi i dominikanie w Prusach - działania misyjne zakonów w latach trzydziestych XIII wieku. Rywalizacja czy współpraca?" in Cystersi, hrsg. v. Wyrwa und Dobosz, 232-234, 249; Rafał Kubicki, Środowisko dominikanów kontraty pruskiej od XIII do potowy XVI wieku (Gdańsk: Wydawnictwo Uniwersytetu Gdańskiego, Muzeum Archeologiczne, 2007), 22, 46.

7 Dariusz Aleksander Dekański, "Próba uporządkowania kierunków i chronologii misji św. Jacka. Między hagiografią a » uczoną « historiografią," in Święty Jacek Odrowąz i dominikanie na Śląsku, hrsg. v. Antoni Barciak (Katowice: Polska Akademia Nauk, 2008), 88-89. 
Personen aus der polnischen Provinz der Dominikaner. ${ }^{8}$ Kurz darauf, d. h. mit der Bulle vom 30. Mai I 236, ermächtigte Gregor IX. in Terni seinen Legaten Wilhelm von Modena zur Aufteilung Preußens in drei Diözesen. Auf Rat und mit dem Einverständnis des Deutschen Ordens sollten drei Dominikaner die Bistümer, welche dort entstehen sollten, als Bischöfe besetzen. ${ }^{9}$ Wilhelm von Modena übte, ähnlich wie Gregor IX., die Schirmherrschaft über die Predigerbrüder und die Deutschordensritter aus, die Angelegenheit der Christianisierung Preußens dagegen - welche vorübergehend ausschließlich durch diese zwei Orden geführt worden war erwies sich als besonders dringend. ${ }^{10}$ Auf das päpstliche Wohlwollen zählten sowohl der Deutsche Orden als auch die Dominikaner. ${ }^{11}$ Ein Zusammenhang zwischen dem Treffen in Marienwerder und der Bulle vom 30. Mai I 236 liegt auf

8 Codex diplomaticus Prussicus. Urkunden-Sammlung zur ältern Geschichte Preusens aus dem Königl. Geheimen Archiv zu Königsberg nebst Regesten, Bd. I, hrsg. v. Johannes Voigt (Königsberg: Bornträger, I 836), Nr. 46; Preußisches Urkundenbuch, I. I, hrsg. v. Philippi, Nr. 53; Max Perlbach, "Zur Geschichte des ältesten Grossgrundbesitzes im Deutschordenslande Preussen. Dietrich von Dypenow und Dietrich Stange," Altpreußische Monatsschrift 39 (1902): 78-80, ı 03-ı 04; Jan Powierski, “Źuława Kwidzyńska i jej zaplecze osadniczo-własnościowe w Pomezanii na Pojezierzu Iławskim w średniowieczu (w świetle źródeł pisanych). Cz. I - Tereny nad średnią Liwą i w okolicach Postolina," in Osadnictwo nad Dolnq Wista w Średniowieczu, hrsg. v. Stanisław Gierszewski (Warszawa: Wydawnictwa Uniwersytetu Warszawskiego, 1989), 74-75; Dekański, Początki, I64, I7 I-173, I77; Błażej Siuchniński, "Kształtowanie sieci diecezjalnej w Prusach na tle zaangażowania dominikanów i udziału św. Jacka w misji pruskiej," in Święty Jacek i dziedzictwo dominikańskie, hrsg. v. Erwin Mateja, Anna Pobóg-Lenartowicz, und Maria Rowińska-Szczepaniak (Opole: Wydawnictwo Uniwersytetu Opolskiego, 2008), 5I4-5is.

9 Codex diplomaticus Prussicus, I, hrsg. v. Voigt, Nr. 47; Preußisches Urkundenbuch, I.I, hrsg. v. Philippi, Nr. I 25 ; siehe auch Dekański, Próba, 90. Wer von Preußen zum Apostolischen Stuhl über diese wichtigen Bestimmungen die Nachricht fuhr, ist unbekannt. Vielleicht machte es einer von zwei Dominikaner, Martin oder Benigny, die im Jahre I235 Wilhelm von Modena während seiner Gesandtschaft in Preußen begleiteten, siehe Preußisches Urkundenbuch, I. I, hrsg. v. Philippi, Nr. I i 9; Iben Fonnesberg-Schmidt, The Popes and the Baltic Crusades I 147-I254 (Leiden-Boston: Brill, 2007), I 74.

10 Donner, Kardinal Wilhelm, 272; Jacek Woroniecki, Św. Jacek Odrowąż i wprowadzenie zakonu kaznodziejskiego do Polski (Katowice: Księgarnia św. Jacka, I 947), I 35 ; Bodański, "Początki hierarchii," 344; Jan Powierski, "Świętopełk gdański i Kazimierz kujawsko-łęczycki w rywalizacji z zakonem krzyżackim o ziemie bałtyjskie w latach I 250 - połowa I 252," Rocznik Gdański 4I, Nr. I (I98 I): 47; Anna Wiśniewska, Henryk-Heidenryk pierwszy biskup chetmiński (Pelplin: Wydawnictwo Diecezjalne, I992), 2 I-22; Andrzej Radzimiński, "Dominikanie toruńscy na tle życia zakonnego w państwie zakonu krzyżackiego w Prusach," in Klasztor dominikański w Toruniu. W75o. rocznice fundacji, hrsg. v. Piotr Oliński, Waldemar Rozynkowski und Juliusz Raczkowski (Toruń: Wydawnictwo Naukowe Uniwersytetu Mikołaja Kopernika, 20 I 3), 9- Io; Fonnesberg-Schmidt, The Popes, 2 I I.

i1 Siuchniński, "Kształtowanie," 520. 
der Hand. ${ }^{12}$ Während der Abwesenheit des Bischofs Christian könnte ein gemeinsamer Plan zur neuen Diözesenaufteilung Preußens in Marienwerder entstanden sein $^{13}$. Ein Ergebnis der Gespräche war offenkundig die gemeinsame Bittschrift an die päpstliche Kurie, welche die Diözesenaufteilung Preußens betraf. Diese Bittschrift führte dann zur Entstehung der erwähnten Bulle. Ob dies durch die Vermittlung der Oberen beider Orden erfolgte, d. h. des Hochmeisters Hermann von Salza (I 209-1 239) und des Ordensgenerals Jordan von Sachsen (I 222-I 237), ist nicht bekannt ${ }^{14}$. Die Tatsache, dass beide aus dem Heiligen Römischen Reich und demselben sprachlichen Umfeld stammen, könnte meiner Meinung nach zu einer Zusammenarbeit geführt haben. Die Aktion der Deutschordensritter und der Dominikaner hätte in diesem Fall, bei vollkommener Zustimmung des Apostolischen Stuhls, eine Schwächung der Position der Zisterzienser in Preußen zum Ziel gehabt. ${ }^{15}$ Eine ihrer Folgen war die Zerstörung des Bischofssitzes von Christian in Zantir durch den Deutschen Orden im Jahre I 236. Den Deutschordensrittern oblag fortan die Oberherrschaft im Gebiet der preußischen Mission. ${ }^{16}$

Die Beweggründe dafür, dass Gregor IX. den Beschluss vom 30. Mai I 236 veröffentlichte, standen im Zusammenhang mit der Absicht die Deutschordensritter und die Dominikaner mit der päpstlichen Kurie zu verbinden, und zwar im Angesicht der mit dem Kaiser Friedrich II. (I 220-I 250 ) geführten Auseinandersetzung. Der päpstliche Verzicht auf Christian war offenkundig eine Reaktion auf

12 Ebd., 5 I 5 .

13 Jan Powierski, "Początek walk Krzyżaków o panowanie nad Zalewem Wiślanym i założenie Elbląga," Nautologia 28, Nr. 3 (1993), 7; Dekański, Początki, 173; siehe auch Siuchniński, "Kształtowanie", 5 I 5, 520; vgl. Jerzy Kłoczowski, Wspólnoty zakonne w średniowiecznej Polsce (Lublin: Wydawnictwo KUL, 2010), i 54.

14 Siehe Helmuth Kluger, Hochmeister Hermann von Salza und Kaiser Friedrich II. Ein Beitrag zur Frühgeschichte des Deutschen Ordens, Quellen und Studien zur Geschichte des Deutschen Ordens 37 (Marburg: N. G. Elwert, 1987), 173-1 74; Heribert Ch. Scheeben, Beiträge zur Geschichte Jordans von Sachsen, Quellen und Forschungen zur Geschichte des Dominikanerordens in Deutschland 35 (Vechta: Albertus-Magnus-Verlag / Leipzig: Harrassowitz, I938), passim; Donner, Kardinal Wilhelm, 247.

is Vgl. Fonnesberg-Schmidt, The Popes, 200-202. Sylvain Gouguenheim, "Gregor IX., Wilhelm von Modena und die Herrschaftsbildung des Deutschen Ordens (vom Kruschwitzer Vertrag zur Bulle von Rieti I 230-I 234)," in Die Ritterorden als Träger der Herrschaft: Territorien, Grundbesitz und Kirche, hrsg. v. Roman Czaja und Jürgen Sarnowsky, Ordines Militares. Colloquia Torunensia Historica XIV (Toruń: Wydawnictwo Uniwersytetu Mikołaja Kopernika, 2007), 89, stellte fest, dass Gregor IX. eine Politik führte, in der die Deutschordensritter, die Predigerbrüder und Wilhelm von Modena als Legat zusammenarbeiten und die alte Verbindung zwischen dem Bischof Christian, den Zisterziensern und der Metropole von Gnesen ersetzen sollten.

${ }_{16}$ Preußisches Urkundenbuch, I.I, hrsg. v. Philippi, Nr. I34; Powierski, Początek, 7; Dekański, Początki, 173-174; Grochowski, Chrystian, 230. 
die Ergebnisse seiner Tätigkeit in Preußen. ${ }^{17}$ Er resultierte wohl auch aus der Sache, dass Christian in die Fußstapfen der livländischen Zisterzienserbischöfe treten könnte. Preußen, das er gleichsam als sein Territorium behandelte, wäre dann zum Faustpfand für die Stellung einen Reichsfürsten beim Kaiser geworden. ${ }^{18}$ Die positive Berichterstattung des Legaten Wilhelm von Modena über die Tätigkeit der Deutschordensritter und der Dominikaner soll nämlich einen Einfluss auf die von Gregor IX. getroffene Entscheidung ausgeübt haben. Wilhelm kam während seines halbjährigen Aufenthaltes im Jahre I 235 mit der Mission beider Orden in Preußen in Berührung. Er hielt sich dann von Dezember 1235 bis zum Januar I 236 in Rom auf. Der Legat soll die genannte Entscheidung Gregors IX. mitgestaltet haben. ${ }^{19}$

Die Deutschordensritter entschieden sich meiner Meinung nach dagegen zur Zusammenarbeit mit den Dominikanern, da sie wahrscheinlich nicht über entsprechendes Personal zur Besetzung der Bistümer verfügten. Daneben gab es zu dieser Zeit nur die Predigerbrüder, die damals gegenüber dem Deutschen Orden sehr wohlwollend waren, als Geistliche in Preußen, wenn man von den Zisterziensern absieht. Mit einem Wort, die Position der Deutschordensritter war nicht ausreichend stark und sie brauchten Verbündete. Die Dominikaner durften zudem keine Güter besitzen, ${ }^{20}$ wie sich aus ihrer Regel ergab und worin sie sich völlig von den Zisterziensern unterschieden. ${ }^{21}$ Sie konnten daher zu keiner Konkurrenz für den Deutschen Orden bei der Territorialisierung werden, ${ }^{22}$ die eben auf dem Erwerb und Gebrauch von Grundbesitz beruhte.

Die hauptsächlichen Nutznießer der gemeinsamen Aktion von 1236 waren meines Erachtens zweifelsohne die Predigerbrüder. Sie sollten die Bistümer beset-

17 Es geht um die Tatsache, dass die Mission, die unter der heidnischen Prußen in friedlicher Weise geführt wurde, nicht die erwarteten Ergebnisse vorgebracht hat. Die Fortschritte missio militaris des Deutschen Ordens dagegen erweckte in der päpstlichen Kurie, trotz einiger Zweifel, große Zufriedenheit, siehe R. Bodański, "Początki hierarchii," 344, $350-35$ I.

18 Marian Dygo, Studia nad poczatkami wtadztwa zakonu niemieckiego w Prusach (1226-I259) (Warszawa: Uniwersytet Warszawski, I 992), 2 I 3.

19 Donner, Kardinal Wilhelm, 247. Es sollte auch darüber informiert werden, dass Wilhelm von Modena bei dieser Entscheidung in Terni nicht persönlich war, denn er seit Januar I 236 auf einer Legationsreise war, siehe ebd., I 86- I 88.

20 De oudste Constituties van de Dominicanen. Voorgeschiedenis, tekst, bronnen, onstaan en ontwikkeling (I2IS-I237), hrsg. v. Antoninus Hendrik Thomas (Leuven: Universiteitsbibliotheek, 1965), 360, dist. II, cap. 26; siehe auch u. a. William A. Hinnebusch, The History of Dominican Order. Origins and Growth to I50o, Bd. I (New York: Alba House, 1965), I 59; ders., "Dominikanie - krótki zarys dziejów," in Dominikanie. Szkice z dziejów zakonu, hrsg. v. Marcin A. Babraj (Poznań: W drodze, I 986), 97; Kubicki, Środowisko, 75.

21 Vgl. Siuchniński, "Kształtowanie”, 520.

$22 \mathrm{Zu}$ diesem Thema siehe u. a. Gouguenheim, Gregor IX., 94-96. 
zen. Dies garantierte den Bischöfen, dass sie zwei Drittel des Grundes jeder Diözese erhielten (die Dominikaner hatten als Prälaten das Recht dazu, über Güter zu verfügen). Das ermöglichte darüber hinaus, bischöfliche Kapitel zu errichten, und desgleichen, die Bistümer dauerhaft zu besetzen. Beides wiederum erleichterte die Entwicklung des Dominikanerordens in der Region. Die analysierte Bulle zeigt die Bedeutung der Predigerbrüder in Preußen und ihren Einfluss auf Gregor IX. gut auf. Davon profitierten auch die Deutschordensritter, denn es gelang ihnen, die Position ihres größten Rivalen, d. h. von Bischof Christian, erheblich zu schwächen. Zusätzlich sollte, gemäß der Bulle vom 30. Mai I236, die Besetzung der preußischen Bistümer mit ihnen abgesprochen werden, woraus sich die Möglichkeit ergab, Einfluss auf die Kandidatenwahl auszuüben. Die Kirchengewalt in Preußen befand sich nun nicht mehr nur in einer Hand, was die Position des Deutschen Ordens stärkte. ${ }^{23}$ Die Deutschordensritter konnten überdies mit Hilfe der Dominikaner die in der Seelsorge durch den Fortfall der Zisterzienser entstandene Lücke füllen, wozu sie als Territorialherrscher ohnehin verpflichtet waren. ${ }^{24}$ Eine weitere Konsequenz aus der Nominierung gut ausgebildeter und straff organisierter Dominikaner für die preußischen Bistümer hätte auch darin bestanden, dass die Christianisierung's wieder an Schwung gewann, was für die vertragschließenden Seiten sehr wichtig war. ${ }^{26}$ Aus der Absprache konnte auch die Zusicherung der Predigerbrüder resultieren, dass der Kreuzzug im Interesse des Deutschen Ordens noch mehr propagiert wurde. Dies eröffnete die Perspektive einer schnelleren Beherrschung Preußens. Das Engagement der Dominikaner bei der Verkündung der Preußenreisen im Interesse der Deutschordensritter garantierte ihnen jedenfalls vielfältige finanzielle Unterstützung. ${ }^{27}$

Der päpstliche Legat Wilhelm von Modena nutzte die päpstlichen Vollmachten indes nicht und teilte I 236 Preußen nicht in Diözesen auf. Auch ernannte er keine Dominikaner zu Bischöfen. Die Ursachen für das Ausbleiben dieser Schritte Wilhelms von Modena sind kaum bekannt, ${ }^{28}$ doch gibt es einige Überlegungen

23 Donner, Kardinal Wilhelm, 247.

24 Vgl. Siuchniński, "Kształtowanie", 520.

25 Es gibt die Ansicht, dass die Priester des Deutschen Ordens entweder gar nicht, oder nur ausnahmsweise an der Christianisierung der Prußen als Missionare teilnahmen. Ihre seelsorgerische Tätigkeit beschränkte sich eher auf die Ritterbrüder ihres eigenen Ordens, siehe "Petri de Dusburg Chronicon terrae Prussiae," hrsg. v. Max Töppen, in Scriptores rerum Prussicarum. Die Geschichstquellen der preussischen Vorzeit bis zum Untergange der Ordensherrschaft, Bd. I, hrsg. v. Theodor Hirsch, Max Töppen und Ernst Strehlke (Leipzig: Verlag von S. Hirzel, I 86 I), 29, B. I, cap. I; Blanke, "Die Entscheidungsjahre," $4 I I$.

26 Dygo, Studia, 226.

27 Fonnesberg-Schmidt, The Popes, 253, siehe auch: 200, 207.

28 Siuchniński, "Kształtowanie", 5 I 6. 
zu diesem Thema. So besteht die Annahme, dass Christian, I 236 oder I 237/ 238 aus der prußischen Haft entlassen, die Aufteilung vermieden habe. ${ }^{29}$ Er schickte stattdessen eine Beschwerde über die ganze Angelegenheit an den Papst, damit dieser eine Entscheidung fällte. ${ }^{30}$ Gregor IX. kam den Argumenten Christians tatsächlich nach. Am I I. April I 240 befahl er drei Personen, darunter Wilhelm von Modena, den Bischof unter ihre Obhut zu nehmen und ihm die Beachtung seiner Rechte zu sichern. Falls notwendig, sollten sich beide Konfliktparteien an den Apostolischen Stuhl wenden. ${ }^{3 \mathrm{I}}$ Der Tod Gregors IX. von I 24 I, der sehr kurze, nur siebzehn Tage lang dauernde Pontifikat seines Nachfolgers Coelestin IV. und die Sedisvakanz bis zum 25. Juni 1243 zogen meiner Meinung nach die Angelegenheit in die Länge.

29 Die erste Konzeption stellt fest, dass im Jahre ${ }_{2} 36$ Wilhelm von Modena zusammen mit den Deutschordensrittern die neu geschaffenen Diözesen markiert und beschrieben hat, und baldige ihre Ankündigung und Besetzung durch Bischöfe Christian angehalten hat, welcher gerade aus der Gefangenschaft entlassen worden ist, vgl. Johannes Plinski, Die Probleme historischer Kritik in der Geschichte des ersten Preussenbischofs zugleich ein Beitrag zur Geschichte des Deutschen Ritterordens (Breslau: Buchdruckerei der Schlesischen Volkszeitung, 1903), 74, Anm. I; siehe auch: 76-78. Die zweite Konzeption nimmt - in Bezug auf die erste - an, dass im Frühling I 236 - Frühling I 237 Wilhelm die Grenzen der Bistümer, was zeitaufwendig war, markierte. Im Frühjahr I 237 erhielt er einen dringenden päpstlichen Auftrag nach Livland zu gehen und circumscriptio dioecesium wollte er nach seiner Rückkehr beenden. Als es I 239 geschah, im Jahre 1238 Christian erlangte die Freiheit wieder. Er beabsichtigte der einzige Preußenbischof zu bleiben - er hatte dazu entsprechende Urkunden - und sich mit Entschlossenheit gegen diese Aufteilung richtete. Unter diesen Bedingungen war die Ausführung des Befehls sehr schwierig und Wilhelm musste es verschieben, vgl. Donner, Kardinal Wilhelm, 247-249; siehe auch: 1 89, 193, I98-199. Noch eine andere Konzeption sagt, dass die Aufteilung durch Christen blockiert wurde, der im Jahre I 236 oder zu Beginn des Jahres I 237 aus der Gefangenschaft entlassen worden ist. Wilhelm hat mit dem Markieren von Grenzen der Diözesen auch nicht angefangen, da er nicht genug Zeit hatte. Es geschah erst in den Jahren I 239- I 242 - vermutlich näher dem ersten Datum, denn in der Urkunde vom 20. September I 242 wird divisio als „olim celebrata" erwähnt. Es wurde angenommen, dass die neue Diözesanaufteilung Preußens auch vor Christians Beschwerde über den Deutschen Orden zum Apostolischen Stuhl stattfinden musste, und dies geschah am Ende des Jahres 1239 (das wurde auf der Basis der Urkunde vom I I. April I 240 bestimmt), vgl. Donner, Kardinal Wilhelm, 248, 249, Anm. 4; 253-255; Preußisches Urkundenbuch, I. I, hrsg. v. Philippi, Nrn. I 34, I 39; vgl. Grochowski, Chrystian, 237-238.

30 Reh, "Das Verhältnis", 58-60; Plinski, Die Probleme, 85, Anm. 4; Donner, Kardinal Wilhelm, 249; Grochowski Chrystian, 243.

${ }_{31}$ Preußisches Urkundenbuch, I.I, hrsg. v. Philippi, Nr. I 34; Vetera monumenta Poloniae et Lithuaniae gentiumque finitimarum historiam illustrantia: maximam partem nondum edita ex tabularis Vaticanis deprompta collecta ac serie chronologica disposita, Bd. I. Ab Honorio PP. III. usque ad Gregorium PP. XII. I2I7-I409, hrsg. v. Augustin Theiner (Romae: Typis Vaticanis, I 860), Nr. 73. Siehe auch Christoph T. Maier, Preaching the Crusades. Mendicant friars and the cross in the thirteenth century (Cambridge: Cambridge Univ. Press, I 994), 5 I; Fonnesberg-Schmidt, The Popes, 202. 
Die Beschwerde an die päpstliche Kurie bewirkte eine weitere Verschlechterung von Christians Beziehungen zu Wilhelm von Modena. ${ }^{32}$ Der Legat war zwischen 1236 und I 238 sehr für den Deutschen Orden eingestellt. ${ }^{33}$ Er gab auch den Plan der Aufteilung Preußens in mehrere Bistümer nicht auf. I 239 war er der Vermittler für den Vertrag über eine neue territoriale Aufteilung Preußens zwischen dem Deutschen Orden und Bischof Christian. Die Deutschordensritter erhielten zwei Drittel des ganzen Landes - mit dem Vorbehalt, dass es von keiner Bedeutung sei, ob es dort einen oder mehrere Bischöfe geben werde. Darüber hinaus wurden sie von der Pflicht, den Zehnten an die Bischöfe zu zahlen, befreit. ${ }^{34}$ Der Vertrag war ein großer Erfolg für die Deutschordensritter, denn sie hatten nach einer Vereinbarung mit Christian aus dem Jahr I 23 I lediglich ein Drittel des ganzen Landes inne. ${ }^{35}$ Es gelang Christian zwar, ganz Preußen als sein Bistum zu erhalten, doch erlitt er dadurch einen ernsthaften Verlust in seiner Territorialherrschaft. Die Deutschordensritter, die während der Haft Christians wichtige Eroberungen in Preußen gemacht haben, hatten nicht vor, ihm nun zwei Drittel des Territoriums zu überlassen. ${ }^{36}$ Dies galt umsomehr, als sie seit dem 3. August I 234

32 Donner, Kardinal Wilhelm, 256-257.

33 Mehr dazu, vgl. ebd., 208-2 I 7; siehe auch Fonnesberg-Schmidt, The Popes, S. 20 I-202.

34 Donner, Kardinal Wilhelm, 249-25 I. Diese Urkunde ist nicht vorhanden, aber wir wissen über sie aus Notizen, die in anderen Urkunden enthalten geblieben sind, vgl. Preußisches Urkundenbuch, I. I, hrsg. v. Philippi, Nr. I 39 (vom 20. September I 242 und betrifft des Löbauer Landes): inspecta quoque ordinatione olim celebrata inter dominum episcopum Pruscie Xpistianum et fratres de domo Teutonica a domino legato super divisione terre Lubeuo in hunc modum, quod tercia pars ei cedat et due ipsis fratribus; ebd., Nr. I 40 (vom 3 I. Dezember 1242 und betrifft von Samland): nos in predicta terra ex divisione contingit facta per dominum legatum inter dominum episcopum Pruscie et nos, que talis est, quod nobis cedent due partes et ipsi tercia in omni terra subingata vel in posterum subiuganda; ebd., Nr. I 43 (vom 29. Juli I 243 und betrifft des ganzen Preußens): sive unus fuerit episcopus sive plures, fratres duas partes integre cum omni proventu habeant, et episcopus sive episcopi tertiam integre cum omni iurisdictione et iure; siehe auch ebd., Nr. 238 (vom 21. Februar I 25 I und betrifft von Preußen): Cum questio verteretur inter Christianum, primum episcopum Prussie generalem, et fratres domo Theutonica super divisone terrarum et reddituum, et nos in partibus illis tunc temporis plene legationis officio fungeremur, talem de consensu parcium concordiam et transactionem stabilivimus inter eos, quod de terris tunc acquisitis et in posterum acquirendis fratres, qui portant pondus diei et estus, duas partes haberent cum omni temporali proventu, et episcopus terciam cum omni integritate beberet, sic tamen quod in duabus partibus fratrum illud ius haberet spirituale; siehe auch Reh, "Das Verhältnis", 57-58; Donner, Kardinal Wilhelm, 250.

35 Codex diplomaticus Prussicus, I, hrsg. v. Voigt, Nr. 26; Preußisches Urkundenbuch, I.I, hrsg. v. Philippi, Nr. 85.

36 Donner, Kardinal Wilhelm, 250. 
Preußen als päpstliches Lehen innehatten. ${ }^{37}$ Wilhelm von Modena soll sich bei seiner Vermittlung nach den bestehenden Machtverhältnissen gerichtet haben. ${ }^{38}$

Im Vertrag von I 239 dürfte kein Wort über die Dominikaner gefallen sein. $\mathrm{Ob}$ die Predigerbrüder dagegen protestierten, ist unbekannt. Die Situation war meiner Meinung nach für sie umso heikler, als die Vereinbarung territoriale Fragen betraf und sie zu dieser Zeit über keine Güter verfügen durften. ${ }^{39}$ Die Dominikaner strebten danach, ihren Platz in den neu christianisierten Gebieten zu finden. Die Missionseinstellung, der Glaube an die Erlösung für die erbrachten Verdienste bei einer dilatatio fidei in terra paganorum, das Bedürfnis nach Märtyrertum für den Glauben, all dies war bei ihnen stark ausgeprägt. In Preußen konnten sie alle diese Ideen realisieren.

Die Diözesenaufteilung Preußens, die am 30. Mai I 236 festgelegt wurde, interessierte meines Erachtens den Deutschen Orden nur noch wenig. Das Jahr I 236 war, nach der bereits früher erfolgten Eroberung des Kulmerlandes (I 232/I 233) und teilweise auch Pomesaniens ( I 233/I 235), eine Zeit großer Eroberungen des Deutschen Ordens in Preußen. Die Deutschordensritter hatten - sowohl mit Hilfe von Territorialherren und Siedlern aus dem Heiligen Römischen Reich als auch mit Unterstützung des Apostolischen Stuhls - seit dem erwähnten Jahr damit begonnen, alle prußischen Stämme entlang des rechten Ufers der Weichsel, und von da entlang der Weichselnehrung bis hin zum Samland, zu unterjochen. Bis I 239 gerieten die Volksstämme der Pomesanen, Ermländer, Natanger und Barten unter ihre Oberherrschaft. Vom Jahr I 240 datieren die ersten Versuche des Deutschen Ordens, auch das Samland zu erobern..$^{\circ}$ Die Leitung der Eroberungsaktion und der Christianisierung lag fast gänzlich in den Händen der Deutschordensritter. Sie trugen auch den größten Aufwand an Kraft und finanziellen Mitteln. Bis zum Frühling I 243 hatten sie zudem - obwohl nicht endgültig - den Verbündeten der heidnischen Prußen besiegt, nämlich Świętopełk II., den Herzog von Pommerellen (ca. I 220-I266). Dies glückte dank eines Bündnisses mit den Herzögen von Kujavien, Masovien und Großpolen, das der Legat Wilhelm von Modena auf Anweisung der päpstlichen Kurie geschlossen hatte. Der neue Papst Innozenz IV.

37 Preußisches Urkundenbuch, I. I, hrsg. v. Philippi, Nr. Iо8.

38 Donner, Kardinal Wilhelm, 250-25 I.

39 Siehe Sławomir Zonenberg, Stosunki krzyżacko-mendykanckie w Prusach do 1466 roku (Bydgoszcz: Wydawnictwo Uniwersytetu Kazimierza Wielkiego, 20 1 8), 63-64, Anm. 270.

40 Siehe u. a. Biskup und Labuda, Die Geschichte, I63-164; Dygo, "Początki," 66-67. Es sollte auch informieren, dass am I 2. Mai 1237 der Deutsche Orden - was ein großer Erfolg war den Schwertbrüderorden inkorporierte. Auf diese Weise übernahm er seine umfassende Güter in Livland (ein Drittel dieses Gebietes), vgl. Liv-, Est-und Kurländisches Urkundenbuch nebst Regesten, Abt. I, Bd. I, I093-I300, hrsg. v. Friedrich Georg Bunge (Reval: in Commission bei Kluge und Ströhm, I 853 ), Nr. I 49. 
( I 243-I 254) - welcher die Absicht hatte, definitiv mit dem Kaiser Friedrich II. „abzurechnen“ - unterstützte sofort den Deutschen Orden, wobei er die propäpstliche Haltung des neuen Hochmeisters Gerhard von Malberg ( I 24I-I 244) zu

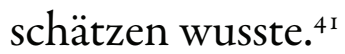

Als im Sommer I 243 Wilhelm von Modena nach Italien zurückkehrte, erstattete er dem Papst Bericht von der Lage in Preußen. Der Legat hatte sicherlich die Skizze der Diözesenaufteilung mitgebracht, welche im Jahre I 239 (eventuell auch I 240-I 242) erstellt worden war ${ }^{42}$. Der Einfluss des Deutschen Ordens unter dem Gerhard von Malberg an der päpstlichen Kurie war sehr groß. Am 28. Juli I 243 teilte Wilhelm von Modena im Auftrag Innozenz IV. das ganze Gebiet, das bisher dem Bischof Christian gehört hatte, in vier Diözesen auf, nämlich Kulmerland, Pomesanien, Ermland und Samland. Auf dem Gebiet Preußens sollte der Deutsche Orden zwei Drittel des Gebietes erhalten, und die Bischöfe nur ein Drittel. ${ }^{43}$ Am nächsten Tag, dem 29. Juli I 243, hat Innozenz IV. diese Aufteilung bestätigt. Damit hatte Christian seine Würde als Bischof von Preußen verloren. ${ }^{44}$ Dies erfolgte zudem in Einvernehmen mit dem Kardinalskollegium, was zeigt, dass es sich um keine willkürliche Entscheidung des Papstes handelte. ${ }^{45}$ Als Grund für die Zuerkennung von zwei Dritteln des Gebietes an den Deutschen Orden stellt eines dieser Dokumente heraus, dass dieser als Eroberer von Preußen mehr Untertanen haben müsse und deshalb auch mehr Land. ${ }^{46}$ Am 30. Juli I 243 schlug der Papst Christian hingegen vor, dass er sich unverzüglich eines der aufgezählten Bistümer aussuchen solle, etwa das Bistum von Kulm, und ansonsten die neue Diö-

41 Biskup und Labuda, Die Geschichte, I66-167; Dygo, "Początki," 67-69; siehe auch Udo Arnold, “Der Deutsche Orden zwischen Kaiser und Papst im I 3. Jahrhundert," in Die Ritterorden zwischen geistlicher und weltlicher Macht im Mittelalter, hrsg. v. Zenon H. Nowak, Ordines Militares. Colloquia Torunensia Historica V (Toruń: Uniwersytet Mikołaja Kopernika, I 990), 64; ders., "Die Staufer und der Deutsche Orden," in Medieval Spirituality in Scandinavia and Europe. A Collection of Essays in Honour of Tore Nyberg, hrsg. v. Lars Bisgaard, Carsten Selch Jensen und Kurt Villads Jensen, Odense University Studies in History and Social Sciences 234 (Odense: Odense Univ. Press, 200 I), i 5 I - I 52.

42 Donner, Kardinal Wilhelm, S. 249, Anm. 4.

43 Preußisches Urkundenbuch, I. I, hrsg. v. Philippi, Nr. I 43.

44 Ebd., Nr. I 42.

45 Ebd., Nr. I 42; Donner, Kardinal Wilhelm, 257.

${ }_{46}$ Preußisches Urkundenbuch, I.I, hrsg. v. Philippi, Nr. I 43: fratres predicti totum pondus expensarum et preliorum sustinent, et quia multis oportet eos infeudare terras; siehe auch ebd., Nr. I 44: fratribus ferentibus preliorum angustias et expensarum onera, quos oportet terram infeudare pluribis. Es ist möglich, dass eine solche Feststellung auch in dieser nichtvorhandenen Urkunde vom I 239 auftrat, siehe Donner, Kardinal Wilhelm, 250. 
zesenaufteilung Preußens zu akzeptieren habe. ${ }^{47}$ Hinter dieser Forderung, welche Christian vor vollendete Tatsachen stellte, standen die Deutschordensritter. ${ }^{48}$ Die wichtigste Änderung im Vergleich zur Bulle vom 30. Mai 1236 bestand darin, dass die Dominikaner in keinem dieser Dokumente Erwähnung finden. ${ }^{49}$ Der Deutsche Orden war offenkundig an der Unterstützung der Dominikaner-Kandidaten nicht mehr interessiert und begann, stattdessen eigene Geistliche für die Bistümer vorzuschlagen. Damit war auch der Vertrag von I 236 nichtig.5

Die Deutschordensritter wollten den Dominikanern wohl keine Bistümer mehr zugestehen, weil dies deren Position in Preußen gefestigt hätte, umso mehr, als ihre Bischöfe zusätzliche Unterstützung in den neu gegründeten Dominikanerklöstern in Kulm (poln. Chełmno) und Elbing (poln. Elbląg) gefunden hätten. ${ }^{\text {st }}$ Dies war im 13. Jahrhundert gängige Praxis geworden. ${ }^{52}$ Im Kreis der Entscheidungsträger des Deutschen Ordens entstand meines Erachtens die Ansicht, dass der örtliche Episkopat, der über ein Drittel des Landes verfügte, eine zusätzliche Unterstützung für ihre Herrschaft sei. Die Beständigkeit konnte aber nur durch eigene, loyale Bischöfe gewährleistet werden. Die preußischen Bischöfe sollten nicht in die Fußstapfen der livländischen Prälaten treten. Diese hatten im ersten Viertel des I 3 . Jahrhunderts Fürstenrang und eine fast vollständige Unabhängigkeit erhalten, indem sie die Regalien vom Kaiser oder römisch-deutschen König annahmen. ${ }^{53}$

Die Deutschordensritter triumphierten, sie besiegten dieses Mal nicht nur den Zisterzienserbischof Christian, sondern auch die Dominikaner. Die Krönung ihres Vorgehens war, dass Hochmeister Gerhard von Malberg am I. Oktober I 243 Preußen als ausschließliches päpstliches Lehen (Investitur mit dem Ring) von In-

47 Preußisches Urkundenbuch, I. I, hrsg. v. Philippi, Nr. I 44; Donner, Kardinal Wilhelm, 258 ; Biskup und Labuda, Die Geschichte, I 50 ; Radzimiński, Geneza, i 45.

48 Kurt Forstreuter, "Darstellung," in Die Berichte der Generalsprokuratoren des Deutschen Ordens an der Kurie, Bd. I, hrsg. v. Kurt Forstreuter (Göttingen: Vandenhoeck \& Ruprecht, I 96 I), 5 I; Fonnesberg-Schmidt, The Popes, 232; siehe auch Sylvain Gouguenheim, Les Chevaliers teutoniques (Paris: Éditions Tallandier, 2007), 240.

49 Preußisches Urkundenbuch, I. I, hrsg. v. Philippi, Nrn. I 42-I 43; Siuchniński, "Kształtowanie," 5i 6.

so Siuchniński, "Kształtowanie," 52 I.

sI Dygo, Studia, 226-227.

s2 Tomasz Jasiński, "Początki klasztoru dominikańskiego w Toruniu," Zapiski Historyczne 54, H. 4 (1989): 26-27.

53 Der Deutsche Orden erkannte den dort bestehenden Sachverhalt nach der Inkorporation des Schwertbrüderordens im Jahre I 237, mehr dazu u. a. Friedrich Benninghoven, Der Orden der Schwertbrüder. Fratres Milicie Christi de Livonia (Köln-Graz: Böhlau, 1965), 74, 77, 357; Bernhart Jähnig, Verfassung und Verwaltung des Deutschen Ordens und seiner Herrschaft in Livland, Schriften der Baltischen Historischen Kommission 16 (Berlin: Lit Verlag, 20 I I ), I 2, I 5. 
nozenz IV. erhielt. ${ }^{54}$ Das war zu dieser Zeit die beste der möglichen Formen der Gewährleistung einer eigenen Herrschaft. ${ }^{55}$ Die Deutschordensritter verfügten zudem über Preußen und das Kulmerland von Seiten des Kaisers. Im Jahre I 226 ( 235 ) hatte Friedrich II. beide Lehen vergeben und sie I 245 dem Deutschen Orden noch einmal bestätigt. ${ }^{56}$ Dieser besaß nun große Chancen, ausschließlicher Herr dieser Gebiete zu werden. Die Deutschordensritter beabsichtigten offenkundig, sich auch in Sachen der Kreuzzugspredigten von den Dominikanern unabhängig zu machen. Sie erhielten am 7. Mai und I3. August I 245 auf eigene Bitte von Innozenz IV. die Erlaubnis zu derartigen Aktivitäten. ${ }^{57}$ Da der Papst schon am I 3. September I 245 die Prälaten erneut ermahnte, den Kreuzzug in Preußen und Livland zu verkünden, ${ }^{58}$ und sich dann gleich mehrfach in derselben Sache auch an die Dominikaner wandte, 59 scheint der Kreuzzugspredigt kein großer Erfolg beschieden gewesen zu sein.

Die Predigerbrüder verzichteten meiner Meinung nach jedoch nicht auf den I 236 von Jacek Odrowąż und Heidenreich vorbereiteten Plan. Heidenreich, der in den Jahren I 238-I 240 polnischer Ordensprovinzial war, begab sich kurz darauf mit einer Mission nach Preußen, wo er zum Kaplan und nächsten Mitarbeiter des Legaten Wilhelm von Modena aufstieg. ${ }^{60}$ Am I6. Januar I 245 erhielt Wil-

54 Preußisches Urkundenbuch, I.I, hrsg. v. Philippi, Nr. I 47; siehe auch Reh, "Das Verhältnis," 63; Biskup und Labuda, Die Geschichte, I 53; Dygo, Studia, 25-27; ders, "Początki," 64.

ss Man darf feststellen, dass Innozenz IV. nicht nur die Politik seines Vorgängers - d. h. Gregor IX., den er Kanzler (Vizekanzler) war - der Unterstützung des Deutschen Ordens fortgesetzt hat. Was mehr, hat er ihn zu einer dominierenden Kraft in Preußen gemacht, trotz der Tatsache, dass die geteilte dort Macht, basierte auf Konkurrenz und Rivalität, wahrscheinlich noch mehr Raum für die Macht des Apostolischen Stuhls überlassen würde.

s6 Preußisches Urkundenbuch, I.I, hrsg. v. Philippi, Nr. 56; Max Perlbach, Preussisch-polnische Studien, H. I (Halle: Max Niemeyer, I 886), Beilagen: Urkunden, Nr. 4; siehe auch Dieter Heckmann, "Die Rückdatierung preußischer Urkunden bis zum Beginn des Prußenaufstandes im Jahr I 242 als Mittel zur Wiedererlangung von Besitz und Rechten," Preußenland 7 (2016): $53-55,6 \mathrm{I}-62$.

57 Codex diplomaticus Prussicus, I, hrsg. v. Voigt, Nrn. 63-64; Preußisches Urkundenbuch, I. I, hrsg. v. Philippi, Nrn. I 67-168.

s8 Codex diplomaticus Prussicus, I, hrsg. v. Voigt, Nr. 65; Preußisches Urkundenbuch, I.I, hrsg. v. Philippi, Nr. 169.

59 Siehe u. a.: Preußisches Urkundenbuch, I. I, hrsg. v. Philippi, Nrn. 242, 25 5, 275, 326; Preußisches Urkundenbuch. Politische (allgemeine) Abteilung, Bd. I, Die Bildung des Ordensstaats, Hälfte 2, hrsg. v. August Seraphin (Königsberg/Pr.: Hartungsche Verlagsdruckerei, I 909), Nrn. I I, I 4 , 23, 30; Vetera monumenta Poloniae et Lithuaniae, I, hrsg. v. Theiner, Nr. I 37.

60 Preußisches Urkundenbuch, I. I, hrsg. v. Philippi, Nr. I64; Codex diplomaticus Warmiensis oder Regesten und Urkunden zur Geschichte Ermlands, Bd. I, Urkunden der Jahre I23I-1340, hrsg. v. Carl Peter Woelky und Johann M. Saage. Monumenta Historiae Warmiensis oder Quellensammlung zur Geschichte Ermlands. I. Abtheilung. Bd. I (Mainz: Kirchheim, I 860), Nr. 9. 
helm in Lyon, wohin er gemeinsam mit Heidenreich gereist war, als Legat eine schriftliche Anweisung in Bezug auf Bischof Christian. Diese sah vor, dass dieser innerhalb von zwei Monaten eine der neu gegründeten preußischen Diözesen für sich auswählte. ${ }^{61}$ Innozenz IV. befand jedoch, dass Wilhelm, den er am 28. Mai I 244 zum Kardinal ernannte, an der päpstlichen Kurie bleiben und ihm beim Regieren behilflich sein solle. ${ }^{62}$ Der Papst beschloss somit, dass Wilhelm bei der genannten Aufgabe, welche Christian betraf, durch seinen Kaplan Heidenreich ersetzt wird. Wilhelm dürfte Heidenreich dem Papst empfohlen haben. ${ }^{63}$ Heidenreich wurde am I. Februar I 245 zum Preußen-Gesandten ernannt, in Vertretung für Wilhelm, der Legat blieb. ${ }^{64}$ Am 6. Februar I 245 wies Innozenz IV. Heidenreich schriftlich an, die Aufgabe, welche sich auf Christian bezog, auszuführen. Bei einer Absage sollte Christian die Bischofswürde verlieren. ${ }^{65}$ Als Heidenreich im Frühling I 245 mit der Bulle in Preußen eintraf, fand er Christian jedoch nicht vor. Dieser hatte sich inzwischen zum Papst und zum Konzil nach Lyon (28. Juni- 17. Juli 1245 ) begeben, um seine Rechte und sein Amt zu verteidigen. ${ }^{66}$ Christian, der mit dem Ruhm eines Missionars und des ersten Bischofs von Preußen auftreten konnte, stellte die neue Diözesenaufteilung dieses Landes auch weiterhin in Frage. Ein Kompromissvorschlag sah die Gründung eines preußischen Erzbistums mit Christian als Metropoliten vor. ${ }^{67}$ Das Verhältnis zwischen Papst und Deut-

61 Preußisches Urkundenbuch, I. I, hrsg. v. Philippi, Nr. I 59; Donner, Kardinal Wilhelm, 286-288; Karol Górski, "Henryk-Heidenreich, pierwszy biskup chełmiński," in Studia nad historia dominikanów w Polsce I222-1972, Bd. I, hrsg. v. Jerzy Kłoczowski (Warszawa: Wydawnictwo Polskiej Prowincji Dominikanów, I975), I 8 I; Wiśniewska, Henryk-Heidenryk, 3 I; Andrzej Nadolny, "Heidenreich," in Die Bischöfe des Heiligen Römischen Reiches II 8 bis I448. Ein biographisches Lexikon, hrsg. v. Erwin Gatz unter Mitwirkung von Clemens Brodkorb (Berlin: Duncker \& Humblot, 200I), $30 \mathrm{I}$.

62 Donner, Kardinal Wilhelm, 28 I, 286, 288; siehe auch Konrad Eubel, Hierarchia catholica medii aevii sive Summorum pontificum, $S$. $R$. E. cardinalium, ecclesiarum antistitum series. Ab anno IIg8 usque ad annum I43 I perducta (Monasterii: Sumptibus et typis Librariae Regensbergianae, I 9 I 3), 7; vgl. Wiśniewska, Henryk-Heidenryk, 3 I.

63 Donner, Kardinal Wilhelm, 286; siehe auch Wiśniewska, Henryk-Heidenryk, 3 I.

${ }^{64}$ Codex diplomaticus Warmiensis, I, hrsg. v. Woelky und Saage, Nrn. 8-9; Preußisches Urkundenbuch, I. I, hrsg. v. Philippi, Nrn. 164-165.

65 Preußisches Urkundenbuch, I. I, hrsg. v. Philippi, Nr. I 66; Reh, "Das Verhältnis," 63; Wiśniewska, Henryk-Heidenryk, 3 I.

66 Jan Powierski, "Chrystian," in Stownik Biograficzny Pomorza Nadwiślańskiego, t. I, hrsg. v. Stanisław Gierszewski (Gdańsk: Wydawnictwo Gdańskie, I 992 ), 2 I 5.

${ }_{77}$ Jan Powierski, "O początkach miasta Chełmży i kapituły chełmińskiej (chełmżyńskiej)," in $O j$ czyzna bliższa i dalsza. Studia historyczne ofiarowane Feliksowi Kirykowi w sześćdziesiatą rocznice urodzin, hrsg. v. Jacek Chrobaczyński, Andrzej Jureczko und Michał Śliwa (Kraków: Wydawnictwo i Drukarnia “Secesja”, I 993), ı o6; ders., Chrystian, 21 5; Jan Wiśniewski, Pomezania. $Z$ dziejów kościelnych (Elbląg: Drukarnia Wydawnictwa Wyższego Seminarium Duchownego 
schem Orden hatte sich zu dieser Zeit abgekühlt. Der neue Hochmeister Heinrich von Hohenlohe ( I 244-I 249), der Nachfolger des propäpstlichen Gerhard von Malberg, der durch die Stauferpartei im Deutschen Orden abgesetzt worden war, stellte sich auf die Seite Friedrichs II. ${ }^{68}$ Der Bruch, zu dem es nun unter den Deutschordensrittern kam, erschwerte ihm allerdings die Tätigkeit. Gerhard von Malberg war überdies mit dem Rücktritt nicht einverstanden und konnte sich mithilfe des Papstes noch für eine gewisse Zeit im Amt halten. ${ }^{69}$

Christian hat die Ernennung zum preußischen Erzbischof indes nicht miterlebt, er verstarb am 4. Dezember I $245 .^{70}$ Das Vorhaben entsprach aber den Vorstellungen des Apostolischen Stuhls. Es gab auch keinen Widerstand seitens des Deutschen Ordens mehr. Die preußischen Bistümer hatten bislang direkt dem Papst unterstanden. Mögliche Ansprüche der Erzbischöfe von Gniezno (dt. Gnesen) auf die kirchliche Oberherrschaft in Preußen, und vor allem im Kulmerland waren damit obsolet geworden. Eine separate Metropole für Preußen und das Kulmerland, welche im Jahr I 246 entstehen sollte, gilt als wichtiger Faktor für die Stärkung der Herrschaft des Deutschen Ordens. ${ }^{71}$ Heidenreich hatte Christian in Preußen nicht angetroffen und beschloss daher, nach Rom zurückzukehren. Am 7. Oktober I 245 bestimmte der Papst, sicherlich im Ergebnis von Unterhandlungen mit Christian, dass Heidenreich die ihm verliehenen Befugnisse aufgeben sollte..$^{72}$ Ende des Jahres I 245 wurde er durch Innozenz IV. zum Bischof von Kulm geweiht. ${ }^{73}$ Seine Nominierung erfolgte meiner Meinung nach wahrscheinlich auf Empfehlung Wilhelms von Modena. Die Predigerbrüder hielten zudem an ihrem Plan fest, die preußischen Bistümer mit eigenen Kandidaten zu besetzen. Außer

"Bernardinum”, I 996), 52; Siuchniński, "Kształtowanie," 5 17. Man stellte richtig fest, dass die Entscheidung von Innozenz IV. das preußische Erzbistum zu gründen, ein Durchbruch in der Politik des Apostolischen Stuhls war. Bisher sah er die preußischen Bistümer als abhängig von Erzbistum von Gnesen, vgl. Gouguenheim, Les Chevaliers, 249.

68 Kurt Forstreuter, Der Deutsche Orden am Mittelmeer, Quellen und Studien zur Geschichte des Deutschen Ordens 2 (Bonn: Verlag Wissenschaftliches Archiv, I 967), 26; Jähnig, Die Staufer, I 47; Arnold, "Der Deutsche Orden," 65; ders., "Die Staufer," I 52 ; ders., "Heinrich von Hohenlohe," in Die Hochmeister des Deutschen Ordens I190-2012, hrsg. v. Udo Arnold, Quellen und Studien zur Geschichte des Deutschen Ordens 40 (Weimar: VDG, 2014 ), 25.

69 Powierski, "O początkach," ı o6; Arnold, "Der Deutsche Orden," 63-67; ders., "Gerhard von Malberg," in Die Hochmeister des Deutschen Ordens IIgo-20I2, hrsg. v. Arnold, 22.

70 Siehe u. a. Grochowski, Chrystian, 299.

${ }_{71}$ Dygo, Studia, 229.

72 Codex diplomaticus Warmiensis, I, hrsg. v. Woelky und Saage, Nr. ıо; Preußisches Urkundenbuch, I.I, hrsg. v. Philippi, Nr. I 70.

73 Wiśniewska, Henryk-Heidenryk, 32-33; Anti Selart, "Die Bettelmönche im Ostseeraum zur Zeit des Erzbischofs Albert Suerbeer von Riga (Mitte des I3. Jahrhunderts)," Zeitschrift für Ostmitteleuropa-Forschung 56, Nr. 4 (2007): 48 I; Siuchniński, "Kształtowanie," 517. 
möglichen geistlichen Verdiensten bei der dilatatio fidei in terra paganorum ging es um viel Landbesitz und damit um eine erhebliche Ausweitung der Handlungsfreiheit des Ordens. Auf Seelsorge und ihre Organisation waren die Dominikaner ohnehin bestens vorbereitet. Innozenz IV. könnte sie dazu bewogen haben, da er zu dieser Zeit Führungspositionen in der kirchlichen Hierarchie ohnehin oft durch Dominikaner - die zur antistaufischen Partei gehörten - besetzen ließ.74 Bereits gemäß der Bulle vom 30. Mai I 236 sollten sie die Bistümer in Preußen erhalten. Nach dem Tod Christians und der Entscheidung zur Gründung eines Erzbistums in Preußen galt es, auch hierfür einen entsprechenden Kandidaten zu finden. Die Deutschordensritter konnten höchstwahrscheinlich keine geeigneten Bewerber stellen und waren überdies mit der Unterdrückung des ersten prußischen Aufstands beschäftigt. ${ }^{75}$ Zum Metropoliten wurde - meines Erachtens wohl auf Vorschlag von Heidenreich - Albert Suerbeer bestellt, ein ehemaliger deutscher Dominikaner (er stammte aus einem Kölner Bürgergeschlecht), Scholastiker mit mehrjähriger Praxis, derzeitig Erzbischof von Armagh und damit Primas von Irland (I 240-I245). Albert konnte sich in Armagh nicht endgültig durchsetzen und weilte spätestens seit I 244 in Frankreich. Er galt als Befürworter der päpstlichen Linie auf dem Konzil in Lyon, an dem er auch persönlich teilnahm. Etwa zur gleichen Zeit erfolgte sein Rücktritt aus dem Erzbistum, das schon im Oktober I 245 als vakant bezeichnet wurde. ${ }^{76}$ Schon am I 3 . Dezember i $245-\mathrm{d}$. h. zu der Zeit, als Heidenreich zum Bischof von Kulm geweiht wurde - bereitete man an der päpstlichen Kurie seine Nominierung zum preußisch-livländisch-est-

74 Siehe Reh, “Das Verhältnis," 77; Dieter Berg, "Papst Innozenz IV. und die Bettelorden in ihren Beziehungen zu Kaiser Friedrich II.," in Vita Religiosa im Mittelalter. Festschrift für Kaspar Elm zum 7o. Geburtstag, hrsg. v. Franz J. Felten, Nikolas Jaspert unter Mitarbeit v. Stefanie Haarländer, Berliner historische Studien 3 I, Ordensstudien I I (Berlin: Duncker \& Humblot, I 999), 466-467; siehe auch Venancio Diego Carro, Święty Dominik Guzmán zatożyciel pierwszego Zakonu Uniwersyteckiego, Apostolskiego i Misyjnego (Poznań: Maschinenschrift in der Bibliothek des Dominikaner-Konvents in Krakau, I 969), 52, hier Angaben, dass während des Pontifikats Gregors IX. 3 I Bischöfe und Prälaten gewählt worden sind, die zum Dominikaner Orden gehörten; dieser Trend blieb auch in der Zeit von Innozenz IV., und zu Beginn des I 4. Jahrhunderts gab es ihnen sogar 150 .

75 Er brach I 243 aus und dauerte mit Intervallen bis I 249, siehe u. a. Biskup und Labuda, Die Geschichte, I67-I7 I; Tomasz Jasiński, "Bitwa nad Jeziorem Rządzkim. Przyczynek do dziejów pierwszego powstania pruskiego i wojny Świętopełka z zakonem krzyżackim," Roczniki Historyczne 62 (1996): 49-5 I; Dygo, "Początki," 69-72.

76 Selart, "Die Bettelmönche," 475-477; siehe auch u. a. Bolesław Kumor, "Albert II Suerbeer OP," in Encyklopedia Katolicka, Bd. I (Lublin: Towarzystwo Naukowe Katolickiego Uniwersytetu Lubelskiego I 973), 300-30 I; Wolfgang Prange und Bernhart Jähnig, "Albert Suerbeer," in Die Bischöfe des Heiligen Römischen Reiches, hrsg. v. Gatz, 647. 
ländischen Metropoliten vor. Diese erfolgte dann am I 0. Januar I 246.77 Nicht nur die preußischen Bischöfe, sondern auch die aus Livland und Estland sollten ihm unterstehen, die Hauptstadt der Metropole sollte sich jedoch in Preußen befinden. Beides zeigt meiner Meinung nach Heidenreichs Einfluss am Apostolischen Stuhl. ${ }^{78}$

Ende des Jahres 1245 fand die päpstliche Kurie einen weiteren Kandidaten für das preußische Bistum, den deutschen Dominikaner Warner (Werner), ein Schützling des Landgrafen von Thüringen Heinrich Raspe (I 227-I247). Dieser wurde bekanntlich am 22. Mai I 246 durch die zur antistaufischen Opposition angehörenden geistlichen Kurfürsten zum römisch-deutschen König gewählt. Die Predigerbrüder, aber auch andere Mendikanten, begannen unterdessen auf Anweisung des Papstes mit einem energischem Aufruf zum Kreuzzug gegen den exkommunizierten Kaiser. ${ }^{79}$ Warner sollte sicherlich die antistaufische Partei in Preußen stärken, die es im Deutschen Orden selbst nach der Beseitigung von Gerhard von Malberg noch gab. An ihrer Spitze stand höchstwahrscheinlich Dietrich von Grüningen, der spätere preußische Landmeister, damals Landmeister in Livland (I 238/ I $239-$ -I 240, I 24I/ I 242-I 246), ein wichtiger Diplomat, der für die Vertretung der Interessen seines Ordens beim Apostolischen Stuhl verantwortlich war. ${ }^{80}$

77 Peter von Goetze, Albert Suerbeer, Erzbischof von Preussen, Livland und Ehstland (St. Petersburg: Buchhandlung von W. Gräff, i 854), I 3; Kurt Forstreuter, "Die Gründung des Erzbistums Preussen I 245/ г 246", Jahrbuch der Albertus-Universität zu Königsberg/Pr. 10 (1960): I I- I 3 , 25-26, Nr. II; vgl. Preußisches Urkundenbuch, I. I, hrsg. v. Philippi, Nr. 176, Anm. S. I 28; siehe auch u. a. Kurt Forstreuter, "Fragen der Mission in Preußen von I 245 bis I 260," Zeitschrift für Ostforschung 9, H. 2/3 (1960): 25 I-252. Es lohnt sich zu informieren, dass im Jahre I 229 Albert Suerbeer nach dem Tode von Albert von Buxthoeven ( I 199-I 229) zum Bischof von Riga ernannt wurde, aber er verlor den Wettstreit um dieses Amt mit Nikolaus von Nauen (I 229- I 253) - siehe u. a. von Goetze, Albert Suerbeer, 2-3; Andrzej Radzimiński, "Podziały kościelne Inflant z Estonią," in Inflanty w średniowieczu. Wtadztwa zakonu krzyżackiego i biskupów, hrsg. v. Marian Biskup (Toruń: Towarzystwo Naukowe w Toruniu, Uniwersytet Mikołaja Kopernika w Toruniu, 2002), 20, 37; Selart, "Die Bettelmönche," 476-477; Maja Gąssowska, "Inflanccy biskupi i arcybiskupi na wygnaniu w XIII i XIV wieku," in Między panem a plebanem. Wieś, miasto, wtadza świecka i duchowna w kulturze średniowiecznej Europy, hrsg. v. Jacek Kowalski und Tomasz Ratajczak (Poznań: Wydawnictwo Poznańskiego Towarzystwa Przyjaciół Nauk, 2013), 5 I.

${ }_{78}$ Vgl. Dygo, Studia, 230.

79 Berg, "Papst Innozenz IV.," 474; siehe auch Reh, "Das Verhältnis”, 77; Selart, “Die Bettelmönche," $48 \mathrm{r}$.

80 Dygo, Studia, 227; Maciej Dorna, Bracia zakonu krzyżackiego w Prusach w latach I228-1309. Studium prozopograficzne (Poznań: Wydawnictwo Poznańskie, 2004), I33-137; siehe auch Robert Gramsch, "Deutschordensdiplomaten in den Verhandlungen zwischen Innozenz IV. und Heinrich Raspe I 244-I 246," in Heinrich Raspe - Landgraf von Thüringen und römischer 
$\mathrm{Zu}$ dieser Zeit hatten meines Erachtens die Dominikaner an der päpstlichen Kurie die Oberhand. Am 2. April 1246 wurde zudem Erzbischof Albert Suerbeer ( I 245/I 246-I 253) zum päpstlichen Legaten mit einem Wirkungsfeld, u. a. in Preußen, Livland und Estland, erhoben. ${ }^{{ }^{8}}$ Eine seiner Aufgaben bestand nach dem Eintreffen vor Ort im Einzug der einst von Christian besessenen Güter, die durch verschiedene Kräfte beansprucht wurden. ${ }^{82}$ Dieses Eigentum sollte zur Kirche zurückkehren. Für die Deutschordensritter ergab sich die Vorgabe, Besitztum, welches sie sich angeeignet hatten, zurückzugeben. ${ }^{83}$ Innozenz IV. verpflichtete sie zudem zur Leistung von Militärhilfe, damit Albert die erwähnten Güter zurückgewinnen konnte. ${ }^{84}$ Ein Dominikaner namens Nikolaus sollte dem Erzbischof vor Ort helfen, denn er galt als stark in Worten und Taten. Zusätzlich war er der prußischen Sprache mächtig. Er sollte dabei von anderen „vorbereiteten und bereiten“ Predigerbrüdern unterstützt werden. ${ }^{85}$ Diese Kumulation von Stellung und Herrschaft für Albert Suerbeer erwies sich als Bedrohung für den Deutschen Orden ${ }^{86}$.

Innozenz IV. richtete am 5. Mai I 246 und erneut am 6. Oktober I 246 ein Schreiben an Erzbischof Albert mit dem Auftrag Warner zum Bischof von Pomesanien, Ermland oder Kurland zu ernennen. ${ }^{87}$ Es galt also für die Dominikaner, so schnell wie möglich ein weiteres Bistum - das schon für die Aufnahme eines Prälaten vorbereitet war - mit einem eigenen Kandidaten zu besetzen. Die Benennung durch den Papst ergab sich aus der Situation, dass es in Preußen noch keine Kapitel gab und die Bischöfe daher durch einen Oberen ernannt werden mussten. ${ }^{88}$ Auch übte Innozenz IV. einen starken Einfluss auf die Besetzung von Diözesen aus. ${ }^{89}$ Der Apostolische Stuhl stellte überdies die Berechtigungen der Erzbischöfe zur Bestätigung der päpstlichen Nominierten in Frage ${ }^{\circ}$. Das weitere Schicksal von Warner ist unbekannt. Nach der Konsekration wurde er möglicherweise nicht nach Preußen gelassen, wo Poppo von Osternohe, ein Befürworter der Staufer,

König (I227-I247). Fürsten, König und Reich in spätstaufischer Zeit, hrsg. v. Matthias Werner, Jenaer Beiträge zur Geschichte 3 (Frankfurt/Main: Peter Lang, 2003), S. 31 7-3 19.

81 Liv-, Est-und Kurländisches Urkundenbuch, I.I, hrsg. v. Bunge, Nr. I 89; Preußisches Urkundenbuch, I.I, hrsg. v. Philippi, Nr. I 80.

82 Forstreuter, "Die Gründung," 26, Nr. III, siehe auch ebd., 27-28, Nr. VII; Gouguenheim, Les Chevaliers, 249.

83 Forstreuter, "Die Gründung," 27, Nr. VI; Gouguenheim, Les Chevaliers, 249.

84 Forstreuter, "Die Gründung," 27, Nr. VI.

85 Ebd., 26-27, Nr. IV; Gouguenheim, Les Chevaliers, 249; Selart, "Die Bettelmönche," 494.

86 Gouguenheim, Les Chevaliers, 250.

87 Preußisches Urkundenbuch, I. I, hrsg. v. Philippi, Nrn. I 86, I 88.

88 Vgl. Dygo, Studia, 228.

89 Ebd., 228.

90 Ebd., 229. 
Landmeister war (I 244-I 247).91 In der Zwischenzeit - Februar-März I 245 kam der Dominikaner Heidenreich als Bischof von Kulm ( I 245- I 263) nach Preußen, zweifelsohne ein Befürworter des Papstes. Dieser gab sich als Vorsitzender des Schiedsgerichtes als Befürworter der Deutschordensritter zu erkennen. ${ }^{92}$ Heidenreich konnte meines Erachtens die Bischofsstellung daher bewahren. I 246 begab sich Hochmeister Heinrich von Hohenlohe nach Preußen und Livland. Sein Ziel, Dietrich von Grüningen und andere dortige Ordensmitglieder auf die staufische Seite zu ziehen, schlug fehl.93

Die Verhinderung der Übernahme der Diözese in Preußen durch Warner hemmte für eine gewisse Zeit eine weitere Nominierung von Bischöfen. Als Poppo von Osternohe als preußischer Landmeister zurücktrat und der propäpstliche Dietrich von Grüningen (1 247-1258/1259) gewählt wurde, trat bald auch der Erzbischof Albert Suerbeer wieder heraus. Ein Erfolg des preußischen Landmeisters Dietrich von Grüningen an der Kurie war es, dass er die Übernahme des Amtes durch Albrecht in Preußen verhinderte. ${ }^{94}$ Innozenz IV. berief zudem den bisherigen Legaten Opizo, Abt des Klosters St. Paul von Mezzano, aus Preußen $a b$, dessen Urteile ungünstig für den Deutschen Orden ausfielen. Im Herbst I 247 berief er stattdessen einen neuen Legaten, und zwar Jakobus Pantaléon, seinen Kaplan und Archidiakon in Lüttich (Liège). Dieser erwies sich jedoch als Befürworter des Deutschen Ordens. ${ }^{95}$ Dietrich von Grüningen, eine der damals hervorragendsten Personen im Deutschen Orden, gehörte zur propäpstlichen Partei. I 246 unterstützte er entschieden die Kandidatur des Landgrafen von Thüringen, Heinrich Raspe, gegen Friedrich II. und dann im Jahre I 247 den Grafen Wilhelm von Holland bei der Wahl zum römisch-deutschen König, welcher Unterstützung bei den geistlichen Kurfürsten fanden. Im Gegenzug erwartete der Landmeister vom Papst, dass Albert Suerbeer den Sitz des Erzbischofs nicht in Preußen, sondern in Livland wählte. ${ }^{96}$ Möglicherweise argumentierte er meiner Meinung nach

91 Vgl. Arnold, "Der Deutsche Orden," 66-67.

92 Preußisches Urkundenbuch, I. I, hrsg. v. Philippi, Nr. I77; Codex diplomaticus Prussicus, I, hrsg. v. Voigt, Nr. 66; siehe auch Powierski, "O początkach," ıо8; Dygo, Studia, 227-228; Wiśniewska, Henryk-Heidenryk, 42.

93 Arnold, "Der Deutsche Orden," 65-66.

94 Prange und Jähnig, "Albert Suerbeer," 647; Jan Powierski, "Książę kujawski i łęczycki Kazimierz a zakon krzyżacki w latach I 248-I 249," Ziemia Kujawska 7 ( 1985 ): 30 ; ders., "O początkach," Iо8.

95 Biskup und Labuda, Die Geschichte, I 69; Powierski, "Książę," 3 I; Dygo, "Początki," 7 I; Fonnesberg-Schmidt, The Popes, 234.

96 Forstreuter, "Fragen," 257-259; ders., "Zur Geschichte des Christburger Friedens von I 249," Zeitschrift für Ostforschung I 2, H. I (1 963): 297-299; Dygo, Studia, 230; Dorna, Bracia zakonu, I 32, I35-137. 
dabei mit dem Aufstand der heidnischen Prußen und fand damit Gehör beim Apostolischen Stuhl und der Gruppe, die Albert unterstützte. Nicht nur Dietrich von Grüningen, der die Rolle des Ordensvertreters immer mehr mit der Funktion eines vertrauten Diplomaten Innozenz' IV. verband, sondern auch die Mehrheit der preußischen Linie der Deutschordensritter, an deren Spitze er stand, befürwortete unterdessen die Seite des Papstes. Der Hochmeister Heinrich von Hohenlohe blieb hingegen ein Befürworter Kaiser Friedrichs II. ${ }^{97}$ Die Deutschordensritter stellten keinen Monolithen dar, was den Dominikanern das Handeln erleichterte. ${ }^{98} \mathrm{Da}$ Albert Suerbeer über keinen beständigen Sitz und somit über keine Einnahmen verfügte, betraute ihn Innozenz IV. in den Jahren I246/I247-I 254 zwecks Sicherung des Unterhaltes mit der Verwaltung zweier deutscher Diözesen, nämlich von Chiemsee (Erzbistum Salzburg) und Lübeck (Erzbistum Bremen). ${ }^{99}$ Man stellte fest, dass er von Lübeck aus - zu dem er I 247 nach dem Tode des dortigen Bischofs Johannes I. (I230/I 23 I-I 247) kam - auch tatsächlich in Sachen Preußens und Livlands intervenieren konnte. ${ }^{100}$

Albert Suerbeer versuchte jedoch, auch einen starken Einfluss auf die Bischofsbesetzung in Preußen auszuüben. Damit hätten sich die territorialen Machtverhältnisse in Preußen entscheidend ändern können. ${ }^{\text {Ior }}$ Zum ersten Bischof von Pomesanien wurde, wahrscheinlich Ende des Jahres I248, der Dominikaner Ernst berufen ( $\dagger$ I 259). ${ }^{102}$ Auch beim Bischof von Natangen (d. h. von Ermland), der I 248 belegt ist und I 250 gemeinsam mit Albert Suerbeer und dem Herzog Świętopełk II. erwähnt wird, könnte es sich um einen Predigerbruder handeln. ${ }^{103}$ Mit Sicherheit wurde I 248 der Dominikaner Heinrich, welcher früher am Hof des Daniel Romanowitsch (I 205/I230-I264) im Fürstentum Halytsch-Wolodymyr belegt ist, durch Albert zum Bischof von Sudauen bestimmt. Der Erzbischof ging in diesem Falle sogar so weit, dass er eine weitere Diözese ins Leben rufen

97 Vgl. Forstreuter, Der Deutsche Orden, 26; Arnold, "Der Deutsche Orden," 65; Dorna, Bracia zakonu, I37.

$9^{8}$ Vgl. Arnold, "Der Deutsche Orden," 66-67.

99 Preußisches Urkundenbuch, I. I, hrsg. v. Philippi, Nrn. I79, I 9 I; Dygo, Studia, 230; Prange und Jähnig, "Albert Suerbeer," 647; Selart, "Die Bettelmönche," 477.

100 Selart, "Die Bettelmönche," 477.

${ }^{101}$ Siuchniński, "Kształtowanie," 520; siehe auch Donner, Kardinal Wilhelm, 294-295.

${ }_{102}$ Reh, "Das Verhältnis," 77; Donner, Kardinal Wilhelm, 294; Powierski, "Ernest," in Stownik Biograficzny Pomorza Nadwiślańskiego, I, hrsg. v. Gierszewski, 390-39 I; Jan Wiśniewski, "Ernst," in Die Bischöfe des Heiligen Römischen Reiches, hrsg. v. Gatz, 565 ; Siuchniński, "Kształtowanie," 5 I 8; siehe auch Selart, "Die Bettelmönche," 48 I.

103 Siuchniński, "Kształtowanie," s 17-5 1 8; Mario Glauert, "Thetward," in Die Bischöfe des Heiligen Römischen Reiches, hrsg. v. Gatz, 679; Powierski, "Świętopełk," so. 
wollte. ${ }^{104}$ Zum ersten Bischof von Samland wurde hingegen der Dominikaner Thetward gekürt, der im Juni 125 I durch Albert auch konsekriert wurde. ${ }^{105}$ Die Kandidatur der erwähnten Personen geschah meines Erachtens zweifellos eine gewisse Zeit vor der Konsekration und wurde sicher in der päpstlichen Kurie genau bedacht, ohne dabei ein secretum officiosum darzustellen. Die Diözesen von Kulm, Pomesanien, Samland und die durch Albert neu gegründete Diözese von Sudauen (die sich später als ephemer erwies), wurden somit durch Predigerbrüder besetzt, vermutlich auch die Diözese von Ermland. Nicht nur Heidenreich, sondern auch Ernst, Thetward und höchstwahrscheinlich Heinrich waren Dominikaner der deutschen Provinz. Sie kamen somit aus dem gleichen kulturellen, politischen und sprachlichen Umfeld wie Albert Suerbeer. ${ }^{106}$

Während der Besetzung der preußischen Diözesen durch die Dominikaner kam es zu einer Veränderung der Haltung der Deutschordensritter, denn sie begannen damit, die eigenen Geistlichen als Kandidaten für diese Stellungen vorzuschlagen. ${ }^{107}$ Als deren Zahl nicht ausreichte, warben sie damit ausgebildete Mitglieder des Dominikanerordens für ihren Orden an. Die Deutschordensritter schickten auch ein Schreiben an den Apostolischen Stuhl, in dem sie behaupteten, dass sie bei der Besetzung preußischer Bistümer diskriminiert würden. Daraufhin wies der Papst Albert Suerbeer am 5. Mai I 246 an, für die nächste preußische Diözese einen Kaplan des Deutschen Ordens zu berufen. ${ }^{108}$ Die Deutschordensritter sollen aber von Beginn an danach gestrebt haben, zumindest zwei Bistümer mit eigenen Geistlichen zu besetzen. ${ }^{\text {Io9 }}$ Der Erzbischof führte die päpstliche An-

${ }^{104}$ Dariusz Dąbrowski, Daniel Romanowicz król Rusi (ok. I20I-I264). Biografia polityczna (Kraków: Wydawnictwo Avalon T. Janowski, 20 I 2), 267, 278-279, 300; Powierski, "O początkach," ı 8; ders., "Świętopełk," 40; ders., "Książę," 43; Siuchniński, "Kształtowanie," 5 I 8-5 19; siehe auch Selart, "Die Bettelmönche," 490.

ros Glauert, "Thetward," 679; Andrzej Radzimiński, "Fundacja i inkorporacja kapituły katedralnej w Chełmży oraz załamanie misji dominikańskiej w Prusach w połowie XIII w." Zapiski Historyczne 56, Nr. 2-3 (I991): I 8; Selart, "Die Bettelmönche," 482; Siuchniński, "Ksztattowanie," 5 I 8; siehe auch Donner, Kardinal Wilhelm, 294-295; Powierski, "Świętopełk," 50-5 I. Thetward wurde unrechtmäßig durch Albert Suerbeer geweiht, denn es ihm die Bulle vom 27. September I 250 verboten hat, vgl. Preußisches Urkundenbuch, I. I, hrsg. v. Philippi, Nr. 236; Codex diplomaticus Warmiensis, I, hrsg. v. Woelky und Saage, Nr. 22; Codex diplomaticus Prussicus, I, hrsg. v. Voigt, Nr. 86.

106 Vgl. Siuchniński, “Kształtowanie," 5 19-520.

107 Ebd., 5 1 9.

${ }_{108}$ Preußisches Urkundenbuch, I.I, hrsg. v. Philippi, Nr. I 87; Codex diplomaticus Prussicus, I, hrsg. v. Voigt, Nr. 68; siehe auch Reh, "Das Verhältnis," 78; Forstreuter, "Die Gründung," I 3; Siuchniński, "Kształtowanie," 5 I 9.

rog Powierski, "O początkach," ıо8. 
weisung allerdings nicht aus. ${ }^{110}$ Erst zur Wende I 248/ 249 ernannte er auf ausdrücklichen Befehl von Innozenz IV. den Deutschordens-Kaplan Heinrich von Strittberg zum Bischof von Ermland (I 248/ I 249-I 250). ${ }^{111}$ Dies geschah zu einer Zeit, als mit Dietrich von Grüningen ein Befürworter des Papstes das Amt des Landmeisters in Preußen bekleidete. Der Apostolische Stuhl war zweifelsohne darum bemüht, durch die Nominierung von Heinrich von Strittberg zum Bischof von Ermland die propäpstliche Orientierung im Deutschen Orden zu festigen. Der Umfang des Einflusses der Deutschordensritter auf die Besetzung preußischer Diözesen hing somit von der aktuellen Einstellung der päpstlichen Kurie ihnen gegenüber und im gewissen Maße auch von dem durch Dietrich von Grüningen ausgeübten Druck auf den Papst ab. ${ }^{12}$ Er stellte sich als äußerst wirksam heraus. Am I o. Januar 249 verpflichtete sich Albert Suerbeer sogar dazu, dass er ohne Einverständnis des Deutschen Ordens keinen Sitz in Preußen nehmen würde. ${ }^{113}$ Der Erzbischof, der sich für den Nachfolger von Bischof Christian hielt, wollte seine Einigung mit den Deutschordensrittern in Sachen der Aufteilung Preußens offenkundig auch ausführen. Im für sie ungünstigsten Fall konnte er bis zu zwei Dritteln des ganzen Gebiets für sich fordern. Am 25. Oktober I 249 verbot Innozenz IV. jedoch den Deutschen Orden zu beunruhigen, die Ursache für diese Anweisung ist nicht bekannt. ${ }^{114}$ Der Erzbischof, der wegen der Bischofserhebungen in einen ernsten Konflikt mit dem Deutschen Orden geraten war, verlor am 27. September 1250 gänzlich die Berechtigung zur Konsekration in Preußen und die Stellung des Legaten in dieser Region. ${ }^{115}$ Seine Position war damit in der Region erheblich geschwächt. ${ }^{116}$ Die Haltung des Papstes gegenüber dem Konflikt

110 Siuchniński, "Kształtowanie," 5 1 9.

II Siehe u. a. Powierski, "Świętopełk," 46; ders., "Książę, 44; Jan Kopiec und Mario Glauert, "Heinrich von Streitberg (Strittberg)," in Die Bischöfe des Heiligen Römischen Reiches, hrsg. v. Gatz, 679 .

112 Dygo, Studia, 228.

113 Preußisches Urkundenbuch, I. I, hrsg. v. Philippi, Nr. 2 17; Dygo, Studia, 230; Selart, "Die Bettelmönche," 478; Gouguenheim, Les Chevaliers, 250. Forstreuter, "Fragen," 26I; Powierski, "Świętopełk," 42-44, datieren diese Urkunde auf I o. Januar 1250.

${ }_{114}$ Preußisches Urkundenbuch, I.I, hrsg. v. Philippi, Nr. 226; siehe auch ebd., Nrn. 22 5, 227; Dygo, Studia, 232.

is Preußisches Urkundenbuch, I.I, hrsg. v. Philippi, Nr. 236; Codex diplomaticus Warmiensis, I, hrsg. v. Woelky und Saage, Nr. 22; Codex diplomaticus Prussicus, I, hrsg. v. Voigt, Nr. 86; von Goetze, Albert Suerbeer, 38 ; Philipp Schwartz, Kurland im dreizehnten Jabrhundert bis zum Regierungsantritt Bischof Emund's von Werd (Leipzig: E. Bidder, I 875), 59-60; Powierski, "Świętopełk," 52; Krzysztof Stopka, "Próby chrystianizacji Litwy w latach I 248- I 263," Analecta Cracoviensia I 9 (1987): I 6; Selart, "Die Bettelmönche," 488-489; Fonnesberg-Schmidt, The Popes, 233; Siuchniński, "Kształtowanie," 5 I 9.

${ }_{116}$ Powierski, "Świętopełk," 52; Gouguenheim, Les Chevaliers, 252. 
zwischen Albert Suerbeer und dem Deutschen Orden war freilich recht inkonsequent. Obwohl er dem Erzbischof große Kompetenzen übertrug, schützte er ihn nicht vor dem Deutschen Orden. Der Metropolit war ein Druckmittel auf den Deutschen Orden, deren Hochmeister ein wichtiges Mitglied der kaiserlichen Partei war. Gleichzeitig jedoch nutzte der Papst die Unterstützung seiner Anhänger innerhalb des Deutschen Ordens, an deren Spitze der preußische Landmeister Dietrich von Grüningen stand. ${ }^{17}$ Am 6. Oktober I 250 bestätigte Innozenz IV. deshalb die Konsekration des Deutschordens-Kaplans Anselm zum Bischof von Ermland (I 250-I 278). Dieser war zuvor Dominikaner, ${ }^{118}$ wurde aber auf Initiative des Deutschen Ordens am 28. August 1250 geweiht. ${ }^{119}$ Der bisherige Bischof von Ermland, der Deutschordens-Kaplan Heinrich von Strittberg, hatte auf den Posten verzichtet, ohne dass der Grund dafür bekannt ist. ${ }^{20}$ Höchstwahrscheinlich lag die Ursache in abweichenden Ansichten gegenüber dem Erzbischof Albert Suerbeer. ${ }^{121}$ Die Entscheidungsgremien des Deutschen Ordens bestimmten kurz darauf Heinrich von Strittberg für eine andere wichtige Stellung.

Die dominikanische Bischöfe, die eine Zusammenarbeit mit den Deutschordensrittern aufnahmen, verfügten meiner Meinung nach folglich über eine realistische Einschätzung der Situation in Preußen, der militärischen Kraft des Ordens, seines Einflusses an der päpstlichen Kurie, beim Kaiser und den Feudalherren im Heiligen Römischen Reich. Der begabteste von ihnen, Heidenreich, wurde samt dem Erzbischof von Gniezno, Pełka (1232-1258), der ein Protektor des Dominikanerordens gewesen war, ${ }^{122}$ zum Schiedsrichter im Konflikt zwischen Świętopełk II., dem Herzog von Pommerellen, und dem Deutschen Orden be-

\footnotetext{
117 Powierski, "Książę," 30.

I1 8 Siehe u. a. Franz Hipler, Bibliotheca Warmiensis oder Literaturgeschichte des Bisthums Ermland, Bd. I (Braunsberg: Wichert, I 872), I o; Hans Schmauch, "Anselm," in Altpreußische Biographie, Bd. I, hrsg. v. Christian Krollmann (Königsberg (Pr.): Gräfe und Unzer Verlag, I 94I), I 5 ; Jan Kopiec, "Anselm," in Die Bischöfe des Heiligen Römischen Reiches, hrsg. v. Gatz, I 8 I .

119 Codex diplomaticus Warmiensis, I, hrsg. v. Woelky und Saage, Nr. 23; Codex diplomaticus Prussicus, I, hrsg. v. Voigt, Nr. 87; Preußisches Urkundenbuch, I. I, hrsg. v. Philippi, Nr. 237; siehe auch von Goetze, Albert Suerbeer, 38; Powierski, "Świętopełk," 5 I; Stanisław Achremczyk, Roman Marchwiński und Jerzy Przeracki, Poczet biskupów warmińskich (Olsztyn: Ośrodek Badań Naukowych im. Wojciecha Kętrzyńskiego I 994), I 3; Jerzy Przeracki, "Anzelm," in Poczet biskupów warmińskich, hrsg. v. Stanisław Achremczyk (Olsztyn: Ośrodek Badań Naukowych im. Wojciecha Kętrzyńskiego, 2008), 7.

${ }_{120}$ Reh, “Das Verhältnis," 86; Powierski, “Świętopełk," 46, 5 I.

${ }^{121}$ Vgl. Reh, "Das Verhältnis," 86; Powierski, "Świętopełk," 46.

${ }_{122}$ Siehe u. a. Ryszard Skrzyniarz, "Pełka," in Encyklopedia Katolicka, Bd. i 5, hrsg. v. Stanisław Wilk (Lublin: Towarzystwo Naukowe Katolickiego Uniwersytetu Lubelskiego, 20 I I), 255; Janusz Bieniak, "Pełka," in Polski Stownik Biograficzny, t. 25, hrsg. v. Emanuel Rostworowski (Kraków: Polska Akademia Umiejętności, i 980), 576.
} 
stellt. Am 25. Oktober 1247 verkündeten beide mit dem Waffenstillstand in Kowalowy Ostrów bei Schwetz (poln. Świecie) an der Weichsel eine Entscheidung, der günstig für den Deutschen Orden ausfiel. ${ }^{123}$ Dieser wurde zur Basis des Friedensvertrages vom 24. November I248, dessen Bedingungen die vollkommende Niederlage von Świętopełk II. bedeuteten. ${ }^{24}$ Der Legat Jakobus von Lüttich war an dem Abschluss beteiligt. Er war auch Vermittler des Friedensabkommens vom 7. Februar I 249 zwischen dem Deutschen Orden und einem Teil des prußischen Adels in Christburg, das ein wesentlicher Erfolg der Deutschordensritter war. ${ }^{125}$ Heidenreich hatte an der Vorbereitung der Bedingungen dieses Friedens Anteil. ${ }^{126}$

Der Deutsche Orden - durch so einen großen Erfolg beflügelt und der Unterstützung des Legaten Jakobus aus Lüttich sicher - trat meines Erachtens energisch die weiteren Verhandlungen, die gegen die dominikanischen Prälaten gerichtet waren, an. Dem i 25 I zum Bischof von Samland berufenen Thetward, dessen Wahl Innozenz IV. nicht anerkannt hatte, machte der Deutsche Orden die Übernahme der Diözese unmöglich. An seine Stelle führte er im Einvernehmen mit dem Apostolischen Stuhl den Franziskaner Johann von Diest (I 25 I-I 254), zugleich Kaplan des römisch-deutschen Gegenkönigs Wilhelm von Holland ( I 247-I 254), ein. Der Deutsche Orden bezog die Minoriten auf diese Weise in seine Auseinandersetzung mit den Dominikanern um die preußischen Bistümer ein. Auch Bischof Heinrich fand bei ihm keine Unterstützung, nachdem ihn Erzbischof Albert Suerbeer zur Mission unter den Sudauern berufen hatte. ${ }^{127}$ Immer wieder kam es nun zur Doppelbesetzung der Diözesen, so in Ermland im Jahre I 248 und im Samland im Jahre 125 I. ${ }^{\mathrm{I} 2}$ Die beiden Prälaten, mit Sicherheit jedoch Thetward († nach I 253), nutzten ihren Bischofstitel. Thetward tat dies in

${ }_{123}$ Preußisches Urkundenbuch, I. I, hrsg. v. Philippi, Nr. I 94.

${ }_{124}$ Ebd., Nr. 2 I 3.

${ }_{125}$ Ebd., Nr. 21 8; Urkundenbuch des Bisthums Culm, Theil I, Das Bisthum Culm unter dem Deutschen Orden I243-I466, hrsg. v. Carl P. Woelky, Neues Preussisches Urkundenbuch. Westpreussischer Theil, II. Abtheilung, Urkunden der Bisthümer, Kirchen und Klöster I (Danzig: Commissionsverlag von Theodor Bertling, I 885), Nr. I 9; Dygo, "Początki," 70-72; Biskup und Labuda, Die Geschichte, I70; Powierski, "Książę," 37-39; siehe auch Stanisław Kujot, Dzieje Prus Królewskich. Cz. I. Do roku I3og (ciag dalszy), Roczniki Towarzystwa Naukowego w Toruniu 2 I (Toruń: nakładem Towarzystwa Naukowego, I 9 I 4), 73 I-744.

${ }_{126}$ Preußisches Urkundenbuch, I. I, hrsg. v. Philippi, Nr. 2 i 8.

${ }_{127}$ Roth, Die Dominikaner, 24; Hans Schmauch, "Die Besetzung der Bistümer im Deutschordensstaate (bis zum Jahre I 4 I O). 2. Teil," Zeitschrift für die Geschichte und Altertumskunde Ermlands 2 I (1923): 3; Radzimiński, "Fundacja," I 8; siehe auch Reh, "Das Verhältnis," 77-78.

${ }_{128}$ Powierski, "O początkach," Io8. 
der Umgebung des Erzbischofs von Trier, Arnold II. von Isenburg (I 242-I 259), eines aktiven Mitglieds der antistaufischen Partei. ${ }^{129}$

Es gelang meiner Meinung nach dem Deutschen Orden insgesamt, was sehr wichtig war, den „monolitischen Block“ der Predigerbrüder zu durchbrechen. In diesen Jahren nahmen die Dominikaner nämlich keine einheitliche Position ein. Heidenreich arbeitete zunächst eng mit dem Deutschen Orden zusammen, ehe er in Konflikt mit ihm geriet. ${ }^{130}$ Ernst führte hingegen seine Auseinandersetzung um die Aufteilung des Bistums auf eher ausgewogene Weise. ${ }^{131}$ Thetward und Heinrich, Bischof von Sudauen, blieben durchgehend auf Seiten des Erzbischofs. ${ }^{132}$

Die im Deutschen Orden auftretenden Unstimmigkeiten hatten meines Erachtens seit einiger Zeit keinen Einfluss auf seine einheitliche Haltung gegenüber den dominikanischen Prälaten, die in Preußen allmählich in die Defensive gerieten. Erzbischof Albert Suerbeer und die Deutschordensritter hatten noch einen ernsten Streit um die Aufteilung von Kurland. Am 2 I. Februar I25 I hatte der Kardinal Wilhelm von Modena eine Urkunde in Lyon ausgestellt, in der er Kurland zu Preußen zählte, um die Regel der territorialen Aufteilung zwischen dem Deutschen Orden und den Bischöfen auch auf diese Diözese anzuwenden. ${ }^{133} \mathrm{Am}$ 24. Februar I 25 I bestätigte Wilhelm in Lyon - samt zwei anderen Kardinälen den Vertrag, den der preußische Landmeister Dietrich von Grüningen und Albert Suerbeer in der Frage einer für die Deutschordensritter günstigen Aufteilung Kurlands geschlossen hatten. ${ }^{134}$ Die Zuerkennung von zwei Drittel Kurlands samt den Zehnten an den Deutschen Orden zeugt von einer schwachen Verhandlungsposition von Erzbischof Albert ihm gegenüber, sowie von einem geringen Einfluss an

${ }_{129}$ Glauert, “Thetward," 679; Antoninus H. Thomas, "Arnold II. (von Isenburg)," in Neue Deutsche Biographie, hrsg. v. Otto Graf zu Stolberg-Wernigerode (Berlin: Duncker \& Humblot, I953): 378 .

130 Urkundenbuch des Bisthums Culm, I, hrsg. v. Woelky, Nr. 52; Preußisches Urkundenbuch, I.2, hrsg. v. Seraphin, Nr. 4I; siehe auch Górski, "Henryk-Heidenryk," i 86; Jasiński, "Początki," 28-29; Wiśniewska, Henryk-Heidenryk, 44-49, 52; Nadolny, "Heidenreich," $30 \mathrm{I}$.

${ }^{131}$ Mehr dazu vgl. Jan Wiśniewski, Dzieje diecezji pomezańskiej (do I360 r.) (Elbląg: Elgraf, I 993), 34-36.

${ }_{132}$ Powierski, "O początkach," i 08 ; siehe auch Selart, "Die Bettelmönche," 49 I 498.

${ }_{133}$ Liv-, Est- und Kurländisches Urkundenbuch nebst Regesten, Abt. I, Bd. III. I. Nachträge zu den zwei ersten Bänden. II. Fortsetzung von 1368-1393, hrsg. v. Friedrich Georg Bunge (Reval: in Commission bei Kluge und Ströhm, I 857), Nr. 217a; Preußisches Urkundenbuch, I.I, hrsg. v. Philippi, Nr. 239.

${ }_{134}$ Liv-, Est-und Kurländisches Urkundenbuch, I.I, hrsg. v. Bunge, Nr. 2 I 8; Preußisches Urkundenbuch, I. I, hrsg. v. Philippi, Nr. 240; Dygo, Studia, 23 I-232; siehe auch siehe auch von Goetze, Albert Suerbeer, 39-40; Schwartz, Kurland, 60-61; Reh, "Das Verhältnis," 82-83; Donner, Kardinal Wilhelm, 402-404. 
der Kurie. ${ }^{135}$ Er unterzeichnete daher am 3. März I 25 I eine Vereinbarung mit den Deutschordensrittern und erfüllte ihre Forderungen, dass nicht eine Ortschaft in Preußen, sondern Riga zum Sitz des Erzbischofs werden sollte. Voraussetzung war der Tod oder die Amtsaufgabe des dort amtierenden Bischofs Nikolaus von Nauen. ${ }^{136}$ Am 9. und I4. März I 25 I bestätigte Innozenz IV. in Lyon die Beschlüsse vom 24. Februar und vom 3. März I 25 I. ${ }^{137}$ Auf diese Weise gelang Dietrich von Grüningen die „Entfernung“von Albert Suerbeer, der von I 253 bis I 272/I 273 in Riga amtieren sollte, aus Preußen. ${ }^{138}$ Die Tatsache, dass Albert Bündnisse mit den Heiden gegen den Deutschen Orden schloss, könnte dazu beigetragen haben. ${ }^{139}$ Als römischer König Konrad IV. († 2 I. Mai I 254 ) und Innozenz IV. († 7. Dezember I 254) kurz beide einander verstarben, führten die Deutschordensritter die Besetzung der preußischen Diözesen durch eigene Geistliche weiter. Sie nutzten meiner Meinung nach dazu die Sedisvakanz in Rom, in der es kein Kirchenoberhaupt gab, an das appelliert werden konnte. ${ }^{140}$ Franziskaner Johann von Diest, der sich als Bischof von Samland als ungeeignet erwies, wurde zur Niederlegung des Amtes gezwungen, seine Stelle nahm der ehemalige Bischof von Ermland, der Deutschordens-Kaplan Heinrich von Strittberg (I 254-I 274), ein. ${ }^{141}$ Das Bistum

135 Reh, "Das Verhältnis," S. 74; Powierski, "Świętopełk," 57-58; Stopka, "Próby chrystianizacji," 17; Dygo, Studia, 232.

${ }^{136}$ Preußisches Urkundenbuch, I.I, hrsg. v. Philippi, Nr. 24 I; Donner, Kardinal Wilhelm, 404-405; Powierski, "Świętopełk," 58; Stopka, "Próby chrystianizacji," I 8; Prange und Jähnig, "Albert Suerbeer," 647-648; Selart, "Die Bettelmönche," 478; Gouguenheim, Les Chevaliers, 253. Es lohnt sich hinzuzufügen, dass in Riga ein Dominikanerkloster existierte, das I 234 unter Beteiligung Wilhelm von Modena errichtet wurde, vgl. siehe Selart, "Die Bettelmönche," 485.

${ }_{137}$ Preußisches Urkundenbuch, I. I, hrsg. v. Philippi, Nrn. 243, 245, siehe auch ebd., Nrn. 244, 246.

${ }_{138}$ Powierski, "Świętopełk," 58-59; siehe auch Fonnesberg-Schmidt, The Popes, 233; Selart, "Die Bettelmönche," 478 .

139 von Goetze, Albert Suerbeer, 35, Anm. 86; siehe auch Schwartz, Kurland, 63; Donner, Kardinal Wilhelm, 404.

140 Vgl. Bodański, "Początki hierarchii," 352.

${ }^{141}$ Urkundenbuch des Bisthums Samland, H. I, hrsg. v. Carl P. Woelky und Hans Mendthal. Neues Preussisches Urkundenbuch. Ostpreussischer Theil. II. Abtheilung: Urkunden der Bisthümer, Kirchen und Klöster. Bd. II (Leipzig: Verlag von Duncker \& Humblot, I 89 I ), Nr. 43; Codex diplomaticus Warmiensis, Bd. II, Urkunden der Jahre I34I-I375 nebst Nachträgen von I240-I340, hrsg. v. Carl Peter Woelky und Johann Martin Saage. Monumenta Historiae Warmiensis oder Quellensammlung zur Geschichte Ermlands I. Abtheilung. Bd. II (Mainz: Kirchheim, I 864), Nr. 5 16; siehe u. a. Perlbach, "Zur Geschichte der ältesten preussischen Bischöfe," 640-642; Glauer, "Thetward," 679; Prange und Jähnig "Albert Suerbeer," 647-648; Kopiec und Glauert, "Heinrich von Streitberg," 679-680; Wolfgang Prange, "Johann von Diest," in Die Bischöfe des Heiligen Römischen Reiches, hrsg. v. Gatz, 352; Krzysztof Rafał Prokop, Polscy biskupi dominikanscy. Stownik biograficzny (Kraków: Drukarnia Akcydensowa Dorosz Andrzej. Wydawnictwo, 2013), I39-1 40. 
von Ermland ging, wie oben gesagt wurde, an den Deutschordens-Kaplan Anselm. ${ }^{142}$ Die Gebiete dieser beider Bistümer lagen gänzlich (Samland) oder größtenteils (Ermland) außerhalb der Reichweite der damaligen Eroberungen durch den Deutschen Orden. ${ }^{\mathrm{I} 33}$ Der Angriff auf das Samland und die benachbarten Gebiete erfolgte in den Jahren I254-1255, als diese den Deutschordensrittern kirchlich bereits unterstellt waren. So war es meines Erachtens beabsichtigt. Der Deutsche Orden erhielt am Io. Mai I 254 eine Bulle von Innozenz IV., die Heidenreich als Bischof von Kulm, Ernst als Bischof von Pomesanien und Anselm als Bischof von Ermland mit dem Schutz des Deutschen Ordens vor Verfolgungen betraute, die er für die Einnahme von Groß Barten und Galinden bekam. ${ }^{144}$ Das erschwerte den beiden dominikanischen Prälaten das Auftreten gegen die Deutschordensritter. Schon am Io. März I 254 hatte Innozenz IV. Albert Suerbeer als seinem Legaten - zu dem er ihn erneut auf dem besprochenen Gebiet ernannte - verboten, Entscheidungen gegen den Willen des Deutschen Ordens zu treffen. ${ }^{145}$ Hinter dieser Entscheidung des Papstes, welche die Deutschordensritter zu Herren der Situation machte, standen meiner Meinung nach offenkundig eben diese. Am 22. Dezember I 254 schlossen sie ein Abkommen mit Ernst, dem Bischof von Pomesanien, wodurch sie einen Tausch der beiderseits besessenen Gebiete tätigten (vereinbart am I 8. März I 250 ). Der Deutsche Orden übergab dem Bischof den südlichen Teil der Diözese als Lehen, ${ }^{146}$ doch war Ernst damit nicht zufrieden. ${ }^{147}$ Im Jahre I 259 verstarb er, ohne dass sich etwas geändert hätte.

Die Deutschordensritter beschlossen meines Erachtens die Eroberung der preußischen Bistümer zu beenden. An Stelle von Ernst wurde der Franziskaner Albert zum Bischof von Pomesanien (I259-I 286) gewählt. Sein gutes Verhältnis zu den Deutschordensrittern führte dazu, dass die Kontrolle der Diözese gänzlich in ihre Hände fiel. Das durch ihn I 284-I285 gestiftete Domkapitel in Marienwerder bestand seit Anbeginn aus Deutschordens-Geistlichen. ${ }^{148}$ Nach dem Tode

142 Siehe u. a. Hipler, Bibliotheca Warmiensis, Io; Schmauch, "Anselm," I 5; Kopiec, "Anselm," I 8 I.

143 Powierski, "Świętopełk," 5 I, 59.

${ }^{144}$ Preußisches Urkundenbuch, I. I, hrsg. v. Philippi, Nr. 288.

I4s Liv-, Est-und Kurländisches Urkundenbuch, I.I, hrsg. v. Bunge, Nr. 262.

${ }^{146}$ Preußisches Urkundenbuch, I. I, hrsg. v. Philippi, Nrn. 233, 30 I; siehe auch Radzimiński, "Geneza," I 52; Wiśniewski, Dzieje, 35-37; Powierski, "Ernest," 390; Prokop, Polscy biskupi, 40; Wiśniewski, "Ernst," 565; vgl. Reh, "Das Verhältnis," 85, 92.

${ }_{147}$ Preußisches Urkundenbuch, I.2, hrsg. v. Seraphin, Nr. I08; Powierski, "Świętopełk," 46; ders., "Krzyżackie podboje ziem nad Zalewem Wiślanym a lubeczanie (od założenia miasta Elbląga do pierwszej lokacji miasta Braniewa)," Nautologia 30, Nr. I ( 1995): S. I9; vgl. Reh, "Das Verhältnis," 92.

${ }^{148}$ Preußisches Urkundenbuch, I.2, hrsg. v. Seraphin, Nrn. 439, 456; Reh, "Das Verhältnis," I 27-I 29; Andrzej Radzimiński, Biskupstwa państwa krzyżackiego w Prusach XIII-XV wieku. 
des Bischofs Heidenreich († 29. Juni I 263) wurde das Kulmer Kapitel hingegen dem Deutschen Orden inkorporiert, und zwar am I. Februar I 264 unter dem nächsten Bischof von Kulm, dem Deutschordens-Kaplan Friedrich von Hausen ( I 264-I 274). Dieser wurde zwar durch das Kapitel gewählt, ist aber sicherlich durch die Deutschordensritter vorgeschlagen worden. ${ }^{149}$ Die Wahl wurde noch am demselben Tag durch den päpstlichen Legaten Anselm, Bischof von Ermland und Deutschordens-Geistlicher, bestätigt. ${ }^{\text {I5o }}$ Die Zustimmung Heidenreichs zur Inkorporation des Kulmer Kapitels in den Deutschen Orden wurde indes erst nach seinem Tode durch den Hochmeister Anno von Sangerhausen (I 256 - I 273), der dafür ein Dominikanerkloster in Thorn stiftete, erklärt. ${ }^{151}$ Dazu kam es am 2. April I 263. ${ }^{152}$ Es könnte scheinen, als ob dies eine übereilte Entscheidung Heidenreichs gewesen wäre, denn lässt sich die Verfügung über den Territorialbesitz eines Bistums mit dem Besitz eines Klosters vergleichen? Meiner Meinung nach scheint es sich jedoch anders verhalten zu haben. Als Heidenreich sein Amt innehatte, besaßen die Dominikaner von den vier bestehenden preußischen Bistümern mit Sicherheit drei (oder sogar alle vier). Doch zum Zeitpunkt des genannten Beschlusses verfügten sie nur noch über eins, nämlich das in Kulm. Alle anderen wurden de iure oder de facto durch den Deutschen Orden kontrolliert. Heidenreich wusste genau, dass das Bistum in Kulm das Schicksal der restlichen Diözesen teilen würde. Er beschloss daher, der Lage vorherzukommen, indem er das Bistum zum Verhandlungsgegenstand machte. So wird klar, wieso der Deutsche Orden mit einem solchen Widerspruch auf die Gründung eines Klosters in Thorn eingegangen ist. ${ }^{153}$

$Z$ dziejów organizacji kościelnej i duchowieństwa (Toruń: Wydawnictwo Uniwersytetu Mikołaja Kopernika, 1999), 43-46; ders., "Geneza," I 47; Mario Glauert, Das Domkapitel von Pomesanien (I284-I527), Prussia Sacra I (Toruń: Wydawnictwo Uniwersytetu Mikołaja Kopernika 2003), I $25-\mathrm{I} 26$.

149 Urkundenbuch des Bisthums Culm, I, hrsg. v. Woelky, Nrn. 7 I -72. Mehr dazu u. a. Radzimiński, "Fundacja," I 9-2 I; ders., "Geneza," I 47.

iso Urkundenbuch des Bisthums Culm, I, hrsg. v. Woelky, Nr. 7 I; siehe auch Radzimiński, “Geneza," I 47.

I5 I Hans Schmauch, "Die Besetzung der Bistümer im Deutschordensstaate (bis zum Jahre I 4 I o)." Zeitschrift für die Geschichte und Altertumskunde Ermlands 20 ( 1919 ): 650-65 I; Dygo, Studia, 268-270; vgl. Górski, Henryk-Heidenryk, i 89.

${ }_{152}$ Preußisches Urkundenbuch, I.2, hrsg. v. Seraphin, Nr. 197.

${ }_{153} \mathrm{Zu}$ diesem Thema siehe Jasiński, "Początki," 24, 32-33; Rafał Kubicki, ”Działalność dominikanów kontraty pruskiej na pograniczu polsko-krzyżackim - okręg klasztorny konwentu w Toruniu w XV w.," in Pogranicze polsko-pruskie i krzyżackie (II), hrsg. v. Kazimierz Grążawski (Włocławek-Brodnica: Lega Oficyna Wydawnicza Włocławskiego Towarzystwa Naukowego, 2007), 376-377. 
Indem die bisherigen Erwägungen zusammengefasst werden gilt es festzustellen, dass bei der Rivalität zwischen dem Deutschen Orden und den Dominikanern um die Besetzung der preußischen Bistümer gänzlich die ersteren gewonnen haben. Die Deutschordensritter taten alles, was in ihrer Macht stand, um nicht zuzulassen, dass in ihrem Staat in Preußen eine von ihnen unabhängige kirchliche Macht entstanden wäre. ${ }^{154}$

\section{PRIMARY SOURCES:}

Codex diplomaticus Prussicus. Urkunden-Sammlung zur ältern Geschichte Preusens aus dem Königl. Geheimen Archiv zu Königsberg nebst Regesten. Bd. I. Herausgegeben von Johannes Voigt. Königsberg: Bornträger, I 836.

Codex diplomaticus Warmiensis oder Regesten und Urkunden zur Geschichte Ermlands. Bd. I. Urkunden der Jahre I23I-I340. Herausgegeben von Carl Peter Woelky und Johann M. Saage. Monumenta Historiae Warmiensis oder Quellensammlung zur Geschichte Ermlands. I. Abtheilung. Bd. I. Mainz: Kirchheim, I 860.

Codex diplomaticus Warmiensis oder Regesten und Urkunden zur Geschichte Ermlands. Bd. II. Urkunden der Jahre 134I-I375 nebst Nachträgen von I240-1340. Herausgegeben von Carl Peter Woelky und Johann Martin Saage. Monumenta Historiae Warmiensis oder Quellensammlung zur Geschichte Ermlands I. Abtheilung. Bd. II. Mainz: Kirchheim, I 864.

De oudste Constituties van de Dominicanen. Voorgeschiedenis, tekst, bronnen, onstaan en ontwikkeling (I215-I237). Herausgegeben von Antoninus Hendrik Thomas. Leuven: Universiteitsbibliotheek, 1965.

Liv-, Est-und Kurländisches Urkundenbuch nebst Regesten. Abt. I, Bd. I. 1093-130o. Herausgegeben von Friedrich Georg Bunge. Reval: in Commission bei Kluge und Ströhm, I 853 (Nachdruck: Aalen: Scientia Verlag, 1967).

Liv-, Est- und Kurländisches Urkundenbuch nebst Regesten. Abt. I, Bd. III. I. Nachträge $z u$ den zwei ersten Bänden. II. Fortsetzung von $1368-1393$. Herausgegeben von Friedrich Georg Bunge. Reval: in Commission bei Kluge und Ströhm, I 857 (Nachdruck: Aalen: Scientia Verlag, 1970).

"Petri de Dusburg Chronicon terrae Prussiae." Herausgegeben von Max Töppen. In Scriptores rerum Prussicarum. Die Geschichstquellen der preussischen Vorzeit bis zum Untergange der Ordensherrschaft. Bd. I, herausgegeben von Theodor Hirsch, Max Töppen und Ernst Strehlke, 24-2 I9. Leipzig: Verlag von S. Hirzel, I 86 I.

Pommerellisches Urkundenbuch. Herausgegeben von Max Perlbach. Danzig: Westpreussischen Geschichtsverein, I 882.

${ }^{154}$ Karol Górski, Zakon Krzyżacki a powstanie państwa pruskiego (Wrocław-Warszawa-Kraków-Gdańsk: Zakład Narodowy im. Ossolińskich 1977), 42; siehe auch Reh, "Das Verhältnis," $138-139$. 
Preußisches Urkundenbuch. Politische (allgemeine) Abteilung. Bd. I. Die Bildung des Ordensstaats, Hälfte I. Herausgegeben von Rudolf Philippi in Verbindung mit [Carl P.] Woelky. Königsberg/Pr.: Hartungsche Verlagsdruckerei, I 882 (Nachdruck: Sidney: Wentworth Press, 20 I 8 ).

Preußisches Urkundenbuch. Politische (allgemeine) Abteilung. Bd. I. Die Bildungdes Ordensstaats, Hälfte 2. Herausgegeben von August Seraphin. Königsberg/Pr.: Hartungsche Verlagsdruckerei, I 909 (Nachdruck: Sidney: Wentworth Press, 20 I 8).

Urkundenbuch des Bisthums Culm. Theil I. Das Bisthum Culm unter dem Deutschen Orden I243-1466. Herausgegeben von Carl P. Woelky, Neues Preussisches Urkundenbuch. Westpreussischer Theil, II. Abtheilung, Urkunden der Bisthümer, Kirchen und Klöster I. Danzig: Commissionsverlag von Theodor Bertling, I 885 (Nachdruck: Lexington: Ulan Press, 2012 ).

Urkundenbuch des Bisthums Samland, H. I. Herausgegeben von Carl P. Woelky und Hans Mendthal. Neues Preussisches Urkundenbuch. Ostpreussischer Theil. II. Abtheilung: Urkunden der Bisthümer, Kirchen und Klöster. Bd. II. Leipzig: Verlag von Duncker \& Humblot, I 89 I.

Vetera monumenta Poloniae et Lithuaniae gentiumque finitimarum historiam illustrantia: maximam partem nondum edita ex tabularis Vaticanis deprompta collecta ac serie chronologica disposita. Bd. I. Ab Honorio PP. III. usque ad Gregorium PP. XII. I217-I409. Herausgegeben von Augustin Theiner. Romae: Typis Vaticanis, I 860 (Nachdruck: Osnabrück: Otto Zeller, I 969).

\section{SECONDARY SOURCES:}

Achremczyk, Stanisław, Roman Marchwiński und Jerzy Przeracki. Poczet biskupów warmińskich. Olsztyn: Ośrodek Badań Naukowych im. Wojciecha Kętrzyńskiego, 1994. Arnold, Udo. "Der Deutsche Orden zwischen Kaiser und Papst im I 3. Jahrhundert." In Die Ritterorden zwischen geistlicher und weltlicher Macht im Mittelalter, herausgegeben von Zenon Hubert Nowak, 57-70. Ordines Militares. Colloquia Torunensia Historica V. Toruń: Uniwersytet Mikołaja Kopernika, 990.

Arnold, Udo. "Die Staufer und der Deutsche Orden." In Medieval Spirituality in Scandinavia and Europe. A Collection of Essays in Honour of Tore Nyberg, herausgegeben von Lars Bisgaard, Carsten Selch Jensen und Kurt Villads Jensen, I 45-I 55 . Odense University Studies in History and Social Sciences 234. Odense: Odense University Press, $200 \mathrm{I}$.

Arnold, Udo. "Gerhard von Malberg." In Die Hochmeister des Deutschen Ordens IIgo-20I2, herausgegeben von Udo Arnold, 22-23. Quellen und Studien zur Geschichte des Deutschen Ordens 40. Weimar: VDG, 2014.

Arnold, Udo. "Heinrich von Hohenlohe." In Die Hochmeister des Deutschen Ordens I Igo-2012, herausgegeben von Udo Arnold, 24-26. Quellen und Studien zur Geschichte des Deutschen Ordens 40. Weimar: VDG, 20 I 4.

Benninghoven, Friedrich. Der Orden der Schwertbrüder. Fratres Milicie Christi de Livonia. Köln-Graz: Böhlau, I 965. 
Berg, Dieter. "Papst Innozenz IV. und die Bettelorden in ihren Beziehungen zu Kaiser Friedrich II." In Vita Religiosa im Mittelalter. Festschrift für Kaspar Elm zum 7o. Geburtstag, herausgegeben von Franz J. Felten und Nikolas Jaspert unter Mitarbeit von Stefanie Haarländer, 46I-48 I. Berliner historische Studien 3 I, Ordensstudien I I. Berlin: Duncker \& Humblot, I 999.

Bieniak, Janusz. "Pełka." In Polski Stownik Biograficzny. Bd. 25, herausgegeben von Emanuel Rostworowski, 574-577. Kraków: Polska Akademia Umiejętności, I980.

Biskup, Marian, und Gerard Labuda. Die Geschichte des Deutschen Ordens in Preußen. Wirtschaft - Gesellschaft - Staat - Ideologie. Osnabrück: Fibre Verlag, 2000.

Blanke, Fritz. "Die Entscheidungsjahre der Preussenmission (I206-I274)." In Heidenmission und Kreuzzugsgedanke in der Deutschen Ostpolitik des Mittelalters, herausgegeben von Helmut Beumann, 389-4I6. Wege der Forschung 7. Darmstadt: Wissenschaftliche Buchgesellschaft, 1963.

Bodański, Roman. "Początki hierarchii kościelnej w Prusach. Część I." Studia Warmińskie 16 (1979): 303-353.

Carro, Venancio Diego. Święty Dominik Guzmán zatożyciel pierwszego Zakonu Uniwersyteckiego, Apostolskiego i Misyjnego. Poznań: Maschinenschrift in der Bibliothek des Dominikaner-Konvents in Krakau, 1969.

Dąbrowski, Dariusz. Daniel Romanowicz król Rusi (ok. I20I-I264). Biografia polityczna. Kraków: Wydawnictwo Avalon T. Janowski, 20 I 2.

Dekański, Dariusz Aleksander. "Cystersi i dominikanie w Prusach - działania misyjne zakonów w latach trzydziestych XIII wieku. Rywalizacja czy współpraca?” In Cystersi w spoteczeństwie Europy Środkowej, herausgegeben von Andrzej Marek Wyrwa und Józef Dobosz, 227-250. Poznań: Wydawnictwo Poznańskie, 2000.

Dekański, Dariusz Aleksander. Początki zakonu dominikanów prowincji polsko-czeskiej. Pokolenie św. Jacka w zakonie. Gdańsk: Wydawnictwo Uniwersytetu Gdańskiego, I 999.

Dekański, Dariusz Aleksander. "Próba uporządkowania kierunków i chronologii misji św. Jacka. Między hagiografią a »uczoną《 historiografią." In Święty Jacek Odrowąż i dominikanie na Ślasku, herausgegeben von Antoni Barciak, 76-95. Katowice: Polska Akademia Nauk, 2008.

Donner, Gustav Adolf. Kardinal Wilhelm von Sabina. Bischof von Modena I222-I234. Päpstlicher Legat in den nordischen Ländern (tI25I). Societas Scientiarum Fennica, Commentationes Humanorum Litterarum II/5. Helsingfors: Societas Scientiarum Fennica, 1929.

Dorna, Marcin. Bracia zakonu krzyżackiego w Prusach w latach I228-1309. Studium prozopograficzne. Poznań: Wydawnictwo Poznańskie, 2004.

Dygo, Marian. "Początki i budowa władztwa zakonu krzyżackiego (I 226-1309)." In Państwo zakonu krzyżackiego w Prusach. Wtadza i spoteczeństwo, herausgegeben von Marian Biskup und Roman Czaja, 53-78. Warszawa: Wydawnictwo Naukowe PWN, 2009 . 
Dygo, Marian. Studia nad poczatkami wtadztwa zakonu niemieckiego w Prusach (I226-I259). Warszawa: Uniwersytet Warszawski, I 992.

Eubel, Konrad. Hierarchia catholica medii aevii sive Summorum pontificum, S. R. E. cardinalium, ecclesiarum antistitum series. Ab anno I Ig8 usque ad annum I43I perducta. Monasterii: Sumptibus et typis Librariae Regensbergianae, I 9 I 3.

Fonnesberg-Schmidt, Iben. The Popes and the Baltic Crusades I I47-I254. Leiden-Boston: Brill, 2007.

Forstreuter, Kurt. "Darstellung." In Die Berichte der Generalsprokuratoren des Deutschen Ordens an der Kurie. Bd. I, herausgegeben von Kurt Forstreuter, 7-169. Göttingen: Vandenhoeck \& Ruprecht, I 96 I.

Forstreuter, Kurt. Der Deutsche Orden am Mittelmeer. Quellen und Studien zur Geschichte des Deutschen Ordens 2. Bonn: Verlag Wissenschaftliches Archiv, 1967.

Forstreuter, Kurt. "Die Gründung des Erzbistums Preussen I245/I246." Jahrbuch der Albertus-Universität zu Königsberg/Pr. Iо (1 960): 9-3 I.

Forstreuter, Kurt. "Fragen der Mission in Preußen von I 245 bis I 260 ." Zeitschrift für Ostforschung 9, H. 2-3 (1960): 250-268.

Forstreuter, Kurt. "Zur Geschichte des Christburger Friedens von i 249." Zeitschrift für Ostforschung I 2, H. I (1963): 295-302.

Gąssowska, Maja. "Inflanccy biskupi i arcybiskupi na wygnaniu w XIII i XIV wieku." In Między panem a plebanem. Wieś, miasto, wtadza świecka $i$ duchowna w kulturze średniowiecznej Europy, herausgegeben von Jacek Kowalski und Tomasz Ratajczak, 43-54. Poznań: Wydawnictwo Poznańskiego Towarzystwa Przyjaciół Nauk, 20 I 3.

Glauert, Mario. Das Domkapitel von Pomesanien (I284-I527). Prussia Sacra I. Toruń: Wydawnictwo Uniwersytetu Mikołaja Kopernika, 2003.

Glauert, Mario. “Thetward." In Die Bischöfe des Heiligen Römischen Reiches II 8 bis 1448. Ein biographisches Lexikon, herausgegeben von Erwin Gatz unter Mitwirkung von Clemens Brodkorb, 679. Berlin: Duncker \& Humblot, $200 \mathrm{I}$.

von Goetze, Peter. Albert Suerbeer, Erzbischof von Preussen, Livland und Ehstland. St. Petersburg: Buchhandlung von W. Gräff, i 854.

Gouguenheim, Sylvain. "Gregor IX., Wilhelm von Modena und die Herrschaftsbildung des Deutschen Ordens (vom Kruschwitzer Vertrag zur Bulle von Rieti I 230-I 234).” In Die Ritterorden als Träger der Herrschaft: Territorien, Grundbesitz und Kirche, herausgegeben von Roman Czaja und Jürgen Sarnowsky, 87- I04. Ordines Militares. Colloquia Torunensia Historica XIV. Toruń: Wydawnictwo Uniwersytetu Mikołaja Kopernika, 2007.

Gouguenheim, Sylvain. Les Chevaliers teutoniques. Paris: Éditions Tallandier, 2007.

Górski, Karol. “Henryk-Heidenreich, pierwszy biskup chełmiński.” In Studia nad historia dominikanów w Polsce I222-I972. Bd. I, herausgegeben von Jerzy Kłoczowski, I78- I 93: Warszawa: Wydawnictwo Polskiej Prowincji Dominikanów, I 975.

Górski, Karol. Zakon Krzyżacki a powstanie państwa pruskiego. Wrocław-Warszawa-Kraków-Gdańsk: Zakład Narodowy im. Ossolińskich 1977. 
Gramsch, Robert. "Deutschordensdiplomaten in den Verhandlungen zwischen Innozenz IV. und Heinrich Raspe I 244-I 246." In Heinrich Raspe - Landgraf von Thüringen und römischer König (I227-I247). Fürsten, König und Reich in spätstaufischer Zeit, herausgegeben von Matthias Werner, 317-358. Jenaer Beiträge zur Geschichte 3. Frankfurt/Main: Peter Lang, 2003.

Grochowski, Paweł. Chrystian. Biskup Prus I2I6-I245 i misja pruska jego czasów. Górna Grupa: Wydawnictwo Verbinum, 20 i 8.

Heckmann, Dieter. "Die Rückdatierung preußischer Urkunden bis zum Beginn des Prußenaufstandes im Jahr I 242 als Mittel zur Wiedererlangung von Besitz und Rechten.” Preußenland 7 (2016): 47-62.

Hinnebusch, William A. "Dominikanie - krótki zarys dziejów." In Dominikanie. Szkice $z$ dziejów zakonu, herausgegeben von Marcin Andrzej Babraj, 83-267. Poznań: W drodze, 1986.

Hinnebusch, William A. The History of Dominican Order. Origins and Growth to I5oo. Bd. I. New York: Alba House, i 965.

Hipler, Franz. Bibliotheca Warmiensis oder Literaturgeschichte des Bisthums Ermland. Bd. I. Braunsberg: Wichert, I 872.

Jasiński, Tomasz. "Bitwa nad Jeziorem Rządzkim. Przyczynek do dziejów pierwszego powstania pruskiego i wojny Świętopełka z zakonem krzyżackim.” Roczniki Historyczne 62 (1996): 49-7 I.

Jasiński, Tomasz. "Początki klasztoru dominikańskiego w Toruniu." Zapiski Historyczne 54. H. 4 (1989): 23-48.

Jähnig, Bernhart. "Die Staufer, der Deutsche Orden und Nordosteuropa." Jabrbuch Preußischer Kulturbesitz I 6 (I 979): I 23 - I 5 I.

Jähnig, Bernhart. Verfassung und Verwaltung des Deutschen Ordens und seiner Herrschaft in Livland. Schriften der Baltischen Historischen Kommission I 6. Berlin: Lit Verlag, $20 \mathrm{II}$.

Kluger, Helmuth. Hochmeister Hermann von Salza und Kaiser Friedrich II. Ein Beitrag zur Frühgeschichte des Deutschen Ordens. Quellen und Studien zur Geschichte des Deutschen Ordens 37. Marburg: N. G. Elwert, 1987.

Kłoczowski, Jerzy. Wspólnoty zakonne w średniowiecznej Polsce. Lublin: Wydawnictwo Katolickiego Uniwersytetu Lubelskiego, 20 i.

Kopiec, Jan. "Anselm." In Die Bischöfe des Heiligen Römischen Reiches IIg8 bis I448. Ein biographisches Lexikon, herausgegeben von Erwin Gatz unter Mitwirkung von Clemens Brodkorb, I 8 I. Berlin: Duncker \& Humblot, 200 I.

Kopiec, Jan, und Mario Glauert. "Heinrich von Streitberg (Strittberg)." In Die Bischöfe des Heiligen Römischen Reiches II98 bis 1448. Ein biographisches Lexikon, herausgegeben von Erwin Gatz unter Mitwirkung von Clemens Brodkorb, 679-680. Berlin: Duncker \& Humblot, $200 \mathrm{I}$.

Kubicki, Rafał. "Działalność dominikanów kontraty pruskiej na pograniczu polsko-krzyżackim - okręg klasztorny konwentu w Toruniu w XV w." In Pograniczepolsko-pruskie i krzyżackie (II), herausgegeben von Kazimierz Grążawski, 373-387. Włocławek- 
-Brodnica: Lega Oficyna Wydawnicza Włocławskiego Towarzystwa Naukowego, 2007.

Kubicki, Rafał. Środowisko dominikanów kontraty pruskiej od XIII do potowy XVI wieku. Gdańsk: Wydawnictwo Uniwersytetu Gdańskiego, Muzeum Archeologiczne, 2007. Kujot, Stanisław. Dzieje Prus Królewskich. Tl. ı. Do roku I309: (ciag dalszy). Roczniki Towarzystwa Naukowego w Toruniu 2 I. Toruń: nakładem Towarzystwa Naukowego, druk S. Buszczyński, i 9 I 4.

Kumor, Bolesław. “Albert II Suerbeer OP.” In Encyklopedia Katolicka. Bd. I, herausgegeben von Feliks Gryglewicz, Romuald Łukaszyk und Zygmunt Sułowski, 300-30 I. Lublin: Towarzystwo Naukowe Katolickiego Uniwersytetu Lubelskiego, 1973.

Maier, Christoph T. Preaching the Crusades. Mendicant friars and the cross in the thirteenth century. Cambridge: Cambridge Univ. Press, i 994.

Nadolny, Andrzej. "Heidenreich.” In Die Bischöfe des Heiligen Römischen Reiches I 198 bis 1448. Ein biographisches Lexikon, herausgegeben von Erwin Gatz unter Mitwirkung von Clemens Brodkorb, 30 I-302. Berlin: Duncker \& Humblot, 200 I.

Perlbach, Max. Preussisch-polnische Studien. H. I. Halle: Max Niemeyer, i 886.

Perlbach, Max. "Zur Geschichte der ältesten preussischen Bischöfe." Altpreußische Monatsschrift 9 (1 872): 628-652.

Perlbach, Max. "Zur Geschichte des ältesten Grossgrundbesitzes im Deutschordenslande Preussen. Dietrich von Dypenow und Dietrich Stange." Altpreußische Monatsschrift 39 (1 902): 78-1 24.

Plinski, Johannes. Die Probleme historischer Kritik in der Geschichte des ersten Preussenbischofs zugleich ein Beitrag zur Geschichte des Deutschen Ritterordens. Breslau: Buchdruckerei der Schlesischen Volkszeitung, I 903.

Powierski, Jan. "Aspekty terytorialne cysterskiej misji w Prusach." In Cystersi w spoteczeństwie Europy Środkowej, herausgegeben von Andrzej Marek Wyrwa und Józef Dobosz, 25 I-270. Poznań: Wydawnictwo Poznańskie, 2000.

Powierski, Jan. "Chrystian." In Stownik Biograficzny Pomorza Nadwiślańskiego. Bd I, herausgegeben von Stanisław Gierszewski, 2 I 4-2 I 6. Gdańsk: Wydawnictwo Gdańskie, I 992.

Powierski, Jan. “Dzieje ziemi pasłęckiej do schyłku XIII w.” In Pastęk: z dziejów miasta i okolic 1297-1997, herausgegeben von Jan Włodarski, 75-224. Pasłęk: Urząd Miasta i Gminy, 1997.

Powierski, Jan. "Ernest.” In Stownik Biograficzny Pomorza Nadwiślańskiego. Bd. I, herausgegeben von Stanisław Gierszewski, 390-391. Gdańsk: Wydawnictwo Gdańskie, 1992.

Powierski, Jan. "Krzyżackie podboje ziem nad Zalewem Wiślanym a lubeczanie (od założenia miasta Elbląga do pierwszej lokacji miasta Braniewa).” Nautologia 30, Nr. I (I 995$):$ I -20 .

Powierski, Jan. "Książę kujawski i łęczycki Kazimierz a zakon krzyżacki w latach I 248 - I 249." Ziemia Kujawska 7 ( 1985 ): 29-57. 
Powierski, Jan. "O początkach miasta Chełmży i kapituły chełmińskiej (chełmżyńskiej)." In Ojczyzna bliższa i dalsza. Studia historyczne ofiarowane Feliksowi Kirykowi w sześćdziesiata rocznice urodzin, herausgegeben von Jacek Chrobaczyński, Andrzej Jureczko und Michał Śliwa, ı I - I23. Kraków: Wydawnictwo i Drukarnia “Secesja”, I 993.

Powierski, Jan. "Początek walk Krzyżaków o panowanie nad Zalewem Wiślanym i założenie Elbląga." Nautologia 28, Nr. 3 ( 1993): 2-22.

Powierski, Jan. "Świętopełk gdański i Kazimierz kujawsko-łęczycki w rywalizacji z zakonem krzyżackim o ziemie bałtyjskie w latach i 250 - połowa I 252." Rocznik Gdański 4 I, Nr. I ( I 98 I ): 37-88.

Powierski, Jan. “Żuława Kwidzyńska i jej zaplecze osadniczo-własnościowe w Pomezanii na Pojezierzu Iławskim w średniowieczu (w świetle źródeł pisanych). Cz. I - Tereny nad średnią Liwą i w okolicach Postolina.” In Osadnictwo nad Dolna Wista w Średniowieczu, herausgegeben von Stanisław Gierszewski, 73-165. Warszawa: Wydawnictwa Uniwersytetu Warszawskiego, i 989.

Prange, Wolfgang. "Johann von Diest." In Die Bischöfe des Heiligen Römischen Reiches I Ig 8 bis 1448 . Ein biographisches Lexikon, herausgegeben von Erwin Gatz unter Mitwirkung von Clemens Brodkorb, 352. Berlin: Duncker \& Humblot, 200 I.

Prange, Wolfgang, und Bernhart Jähnig. "Albert Suerbeer." In Die Bischöfe des Heiligen Römischen Reiches IIg8 bis I448. Ein biographisches Lexikon, herausgegeben von Erwin Gatz unter Mitwirkung von Clemens Brodkorb, 647-648. Berlin: Duncker \& Humblot, $200 \mathrm{I}$.

Prokop, Krzysztof Rafal. Polscy biskupi dominikańscy. Stownik biograficzny. Kraków: Drukarnia Akcydensowa Dorosz Andrzej. Wydawnictwo, 2013.

Przeracki, Jerzy. "Anzelm." In Poczet biskupów warmińskich, herausgegeben von Stanisław Achremczyk, 7. Olsztyn: Ośrodek Badań Naukowych im. Wojciecha Kętrzyńskiego, 2008.

Radzimiński, Andrzej. Biskupstwa państwa krzyżackiego w Prusach XIII-XV wieku. $Z$ dziejów organizacji kościelnej i duchowieństwa. Toruń: Wydawnictwo Uniwersytetu Mikołaja Kopernika, I 999.

Radzimiński, Andrzej. "Dominikanie toruńscy na tle życia zakonnego w państwie zakonu krzyżackiego w Prusach.” In Klasztor dominikański w Toruniu. W 75o. rocznice fundacji, herausgegeben von Piotr Oliński, Waldemar Rozynkowski und Juliusz Raczkowski, 9-23. Toruń: Wydawnictwo Naukowe Uniwersytetu Mikołaja Kopernika, 2013.

Radzimiński, Andrzej. "Fundacja i inkorporacja kapituły katedralnej w Chełmży oraz załamanie misji dominikańskiej w Prusach w połowie XIII w." Zapiski Historyczne 56 , H. 2-3 (I99I): 7-24.

Radzimiński, Andrzej. "Geneza oraz ukształtowanie się organizacji kościelnej ( I 206-I409).” In Państwo zakonu krzyżackiego w Prusach. Wtadza i spoteczeństwo, herausgegeben von Marian Biskup und Roman Czaja, I 43-176. Warszawa: Wydawnictwo Naukowe PWN, 2009. 
Radzimiński, Andrzej. "Podziały kościelne Inflant z Estonią." In Inflanty w średniowieczu. Wtadztwa zakonu krzyżackiego i biskupów, herausgegeben von Marian Biskup, 1 7-42. Toruń: Towarzystwo Naukowe w Toruniu, Uniwersytet Mikołaja Kopernika w Toruniu, 2002.

Reh, Paul. "Das Verhältnis des Deutschen Ordens zu den preußischen Bischöfen im I 3. Jahrhundert." Zeitschrift des Westpreußischen Geschichtsvereins 35 ( I 896): 35- I 39.

Roth, Werner. Die Dominikaner u. Franziskaner im Deutsch-Ordensland Preußen bis zum Jahre 1466. Königsberg i. Pr.: Drewes, I 9 I 8.

Scheeben, Heribert Christian. Beiträge zur Geschichte Jordans von Sachsen. Quellen und Forschungen zur Geschichte des Dominikanerordens in Deutschland 35. Vechta: Albertus-Magnus-Verlag / Leipzig: Harrassowitz, I 938.

Schmauch, Hans. “Anselm.” In Altpreußische Biographie. Bd. I, herausgegeben von Christian Krollmann, I s. Königsberg (Pr.): Gräfe und Unzer Verlag, I 94 I.

Schmauch, Hans. "Die Besetzung der Bistümer im Deutschordensstaate (bis zum Jahre I 4 I0)." Zeitschrift für die Geschichte und Altertumskunde Ermlands 20 (I 9 I 9): 643-752 .

Schmauch, Hans. „Die Besetzung der Bistümer im Deutschordensstaate (bis zum Jahre I 4 I0). 2. Teil." Zeitschrift für die Geschichte und Altertumskunde Ermlands 2 I (1923): I-IO2.

Schwartz, Philipp. Kurland im dreizehnten Jahrhundert bis zum Regierungsantritt Bischof Emund's von Wird. Leipzig: E. Bidder, I 875.

Selart, Anti. "Die Bettelmönche im Ostseeraum zur Zeit des Erzbischofs Albert Suerbeer von Riga (Mitte des I 3. Jahrhunderts)." Zeitschrift für Ostmitteleuropa-Forschung 56, H. 4 (2007): 475-499.

Siuchniński, Błażej. "Kształtowanie sieci diecezjalnej w Prusach na tle zaangażowania dominikanów i udziału św. Jacka w misji pruskiej.” In Święty Jacek i dziedzictwo dominikańskie, herausgegeben von Erwin Mateja, Anna Pobóg-Lenartowicz und Maria Rowińska-Szczepaniak, 5 I I-522. Opole: Wydawnictwo Uniwersytetu Opolskiego, 2008.

Skrzyniarz, Ryszard. "Pełka”. In Encyklopedia Katolicka. Bd. i s, herausgegeben von Stanisław Wilk, 255. Lublin: Towarzystwo Naukowe Katolickiego Uniwersytetu Lubelskiego, 20 II.

Stopka, Krzysztof. "Próby chrystianizacji Litwy w latach i248-I263." Analecta Cracoviensia 19 (1 987): 3-68.

Thomas, Aloys. "Arnold II. (von Isenburg).” In Neue Deutsche Biographie. Bd. I, herausgegeben von Otto Graf zu Stolberg-Wernigerode, 378. Berlin: Duncker \& Humblot, I953.

Wiśniewska, Anna. Henryk-Heidenryk pierwszy biskup chetminski. Pelplin: Wydawnictwo Diecezjalne, I 992.

Wiśniewski, Jan. Dzieje diecezji pomezańskiej (do I 360 r.). Elbląg: Elgraf, I 993. 
Wiśniewski, Jan. "Ernst.” In Die Bischöfe des Heiligen Römischen Reiches I I 8 bis I448. Ein biographisches Lexikon, herausgegeben von Erwin Gatz unter Mitwirkung von Clemens Brodkorb, 565. Berlin: Duncker \& Humblot, 200 I.

Wiśniewski, Jan. Pomezania. $Z$ dziejów kościelnych. Elbląg: Drukarnia Wydawnictwa Wyższego Seminarium Duchownego “Bernardinum”, 1996.

Woroniecki, Jacek. Św. Jacek Odrowąż i wprowadzenie zakonu kaznodziejskiego do Polski. Katowice: Księgarnia św. Jacka, 1947.

Zonenberg, Sławomir. Stosunki krzyżacko-mendykanckie w Prusach do 1466 roku. Bydgoszcz: Wydawnictwo Uniwersytetu Kazimierza Wielkiego, 20 r 8. 